OPEN ACCESS

Edited by:

Eric Eldering,

Academic Medical Center (AMC),

Netherlands

Reviewed by:

Derk Amsen,

Sanquin Research, Netherlands

Dolors Colomer,

Hospital Clínic de Barcelona, Spain

*Correspondence:

Silvia Deaglio

silvia.deaglio@unito.it;

silvia.deaglio@iigm.it

tThese authors have contributed equally to this work

Specialty section

This article was submitted to

Hematologic Malignancies,

a section of the journal

Frontiers in Oncology

Received: 10 September 2018 Accepted: 06 November 2018 Published: 26 November 2018

Citation:

Arruga F, Vaisitti T and Deaglio $S$

(2018) The NOTCH Pathway and lts

Mutations in Mature B Cell

Malignancies. Front. Oncol. 8:550.

doi: 10.3389/fonc.2018.00550

\section{The NOTCH Pathway and Its Mutations in Mature B Cell Malignancies}

\author{
Francesca Arruga ${ }^{1,2 \dagger}$, Tiziana Vaisitti ${ }^{1,2 \dagger}$ and Silvia Deaglio ${ }^{1,2 *}$ \\ ${ }^{1}$ Italian Institute for Genomic Medicine, Turin, Italy, ${ }^{2}$ Department of Medical Sciences, University of Torino, Turin, Italy
}

The systematic application of next-generation sequencing to large cohorts of oncologic samples has opened a Pandora's box full of known and novel genetic lesions implicated in different steps of cancer development and progression. Narrowing down to B cell malignancies, many previously unrecognized genes emerged as recurrently mutated. The challenge now is to determine how the mutation in a given gene affects the biology of the disease, paving the way to functional genomics studies. Mutations in $\mathrm{NOTCH}$ family members are shared by several disorders of the B series, even if with variable frequencies and mutational patterns. In silico predictions, revealed that mutations occurring in NOTCH receptors, despite being qualitatively different, may have similar effects on protein processing, ultimately leading to enhanced pathway activation. The discovery of mutations occurring also in downstream players, either potentiating positive signals or compromising negative regulators, indicates that multiple mechanisms in neoplastic B cells concur to activate $\mathrm{NOTCH}$ pathway. These findings are supported by results obtained in chronic lymphocytic leukemia and splenic marginal zone B cell lymphoma where deregulation of NOTCH signaling has been functionally characterized. The emerging picture confirms that NOTCH signaling is finely tuned in cell- and microenvironment-dependent ways. In B cell malignancies, it contributes to the regulation of proliferation, survival and migration. However, deeper biological studies are needed to pinpoint the contribution of $\mathrm{NOTCH}$ in the hierarchy of events driving $\mathrm{B}$ cells transformation, keeping in mind its role in normal B cells development. Because of its relevance in leukemia and lymphoma biology, the $\mathrm{NOTCH}$ pathway might represent an appealing therapeutic target: the next few years will tell whether this potential will be fulfilled.

Keywords: NOTCH, signaling, gene mutations, B cell development, mature B cell malignancies

\section{INTRODUCTION}

Mature B cell malignancies originate from B lymphocytes that can transform at virtually every stage of the differentiation process, depending on the oncogenic events driving transformation and on accessory stimuli contributing to the accumulation and expansion of malignant B cells (1). Reliance on a combination of cell-intrinsic and -extrinsic factors to drive transformation is a shared feature among this clinically and molecularly heterogeneous group of tumors. In fact, some of the genetic mutations defining these tumors hit on signaling pathways that render neoplastic B cells independent of the 
environment, by driving proliferative or anti-apoptotic pathways, while other mutations target molecular components of microenvironmental signaling networks. The resulting picture is likely responsible for the profound alterations of the phenotype and functional responses of the non-neoplastic elements of the environment that become "tumor-friendly," including $\mathrm{T}$ lymphocytes and macrophages $(2,3)$.

NOTCH pathway is one of the most evolutionarily conserved signaling cascades across species that regulates important cell fate decisions during embryonic development. Physiologically, signaling through $\mathrm{NOTCH}$ family members operates in a context-dependent way promoting cell proliferation, cell death and activating specific differentiation programs (4). In adult tissues, NOTCH-mediated signals are important regulators in the maintenance of self-renewal, contributing for example to myogenesis, neurogenesis and lymphocyte development (5). Considering its multiple roles in a wide range of processes and tissues, aberrations resulting in gain or loss of $\mathrm{NOTCH}$ signaling components and functions have been linked to a variety of disorders including solid cancers (6) and hematological malignancies (7), where NOTCH can act either as an oncogene or as a tumor suppressor. In the past decade an increasing number of reports described recurrent gain-of-function mutations of NOTCH1 and NOTCH2 in lymphoproliferative disorders of the $B$ series, including chronic lymphocytic leukemia (CLL), mantle cell (MCL), splenic marginal zone (SMZL), diffuse large B cell (DLBCL) and follicular (FL), Burkitt's (BL) and Hodgkin's (HL) lymphomas. Non-mutational mechanisms of NOTCH activation have also been reported in multiple myeloma $(\mathrm{MM})(8,9)$.

This review will cover the main aspects of $\mathrm{NOTCH}$ contribution to $\mathrm{B}$ cell malignancies, starting from the mechanisms through which $\mathrm{NOTCH}$ signaling drives normal B lymphocyte development and commitment, in order to understand how pathway deregulation and genetic aberrations may influence B cell transformation.

\section{NOTCH PATHWAY COMPONENTS AND MECHANISMS OF SIGNALING}

Mammals express four NOTCH receptors (NOTCH1-4), each encoded by a different gene, that interact with five different ligands (DLL1,-3,-4 belonging to the Delta-like family and Jagged 1 and-2 which are part of the Serrate family of ligands) (10) (Figure 1). NOTCH receptors are single-pass type I transmembrane proteins showing high structure homology (especially NOTCH1 and NOTCH2) and displaying both common and unique functions. They are synthesized as single precursors that maturate in the Golgi apparatus upon proteolytic cleavage (S1) by a furin-like convertase. Mature receptors expressed on the cell surface are heterodimers composed by an $\mathrm{N}$ terminal extracellular region (EC) non-covalently associated with a transmembrane (TM) domain and a C-terminal intracellular (IC) subunit (11). The EC portion of NOTCH receptors contains a series of epidermal growth factor (EGF)-like repeats (29-36), some of which are crucial in mediating ligand interactions and responses (12). Within the EC domain, the EGF-like repeats are followed by a juxtamembrane negative regulatory region (NRR), which contains three Lin12/Notch repeats (LNRs) and a heterdimerization domain (HD), and which prevents NOTCH activation in the absence of ligands. The IC portion of the receptors consists in a protein-binding RBPJk-associated molecule (RAM), seven ankyrin repeats, and less conserved regions including a transcriptional activation domain (TAD) and a C-terminal region rich in proline, glutamate, serine and threonine (PEST domain), which regulates protein stability and degradation as it contains the substrate site that is recognized by E3 ubiquitin ligases (degron domain) (10, 13). Among family members, NOTCH1 and -2 are the most widely expressed receptors, being present in many tissues at the developmental stage, as well as in adults, while NOTCH3 is found mainly in vascular smooth muscle and pericytes, and NOTCH4 is most highly expressed in endothelium (6).

$\mathrm{NOTCH}$ ligands are also type I TM proteins showing high structural homology within the Delta-like and Serrate families, but their expression patterns are less well characterized than those of the receptors (4) (Figure 1). The strength and outcome of receptor-ligand interactions are modulated by post-translational modifications of $\mathrm{NOTCH}$ receptors. The EGF repeats of NOTCH EC region can be modified by the addition of $\mathrm{O}$-fucose and $\mathrm{O}$-glucose residues, which can in turn lead to further modifications (14). The addition of $O$ fucose by protein $O$-fucosyltransferase 1 (Pofut1) is required for subsequent glycosylation of NOTCH receptors by the Fringe family of glycosyltransferases (Lunatic, Manic and Radical Fringe). Glycolsylation potentiates the interactions of NOTCH receptors with DLLs, while reducing responsiveness to JAGs (15).

Binding of NOTCH to a ligand on neighboring cells leads to a conformational change of the receptor and rescues the inhibition imposed by the NRR, exposing a cleavage site (S2) for ADAM metalloproteases close to the TM domain (16) (Figure 2). ADAM-mediated cleavage releases the TM-IC regions from the EC portion of the receptor and this effect is facilitated by, and partly depends on, a mechanical force delivered to the receptor by the signal-sending cell through ligand endocytosis (17). S2 cleavage generates a short-lived membrane-bound form of $\mathrm{NOTCH}\left(\mathrm{N}_{\mathrm{EXT}}, \mathrm{NOTCH}\right.$ extracellular truncated) that is rapidly further cleaved by the $\gamma$-secretase complex (S3), releasing NOTCH IC domain (NICD) from the membrane and allowing its translocation to the nucleus $(18,19)$. Once in the nucleus, the NICD forms a transcriptional complex, having RBPJk as core DNA-binding factor. By binding the transcription factor, NICD alters the composition of RBPJk-tethered complexes, shifting the composition from that of a repressor to an activator of transcription. Specifically, NICD displaces co-repressor molecules bound to RBPJk, such as HDACs, SHARP, MINT and SPEN (11,20-22) and recruits transcription co-activators of the Mastermind-like family [MAML, (23)], as well as the histone acetyl transferase p300 (24) and the histone demethylase KDM1A [also known as LSD1, (25)], to initiate transcription of NOTCH target genes. Major NOTCH target genes include the basic helix-loop-helic (bHLH) class of transcription factors, such as HES1 and HEY1 (26), which act as repressor of transcription playing critical roles in developmental processes, 


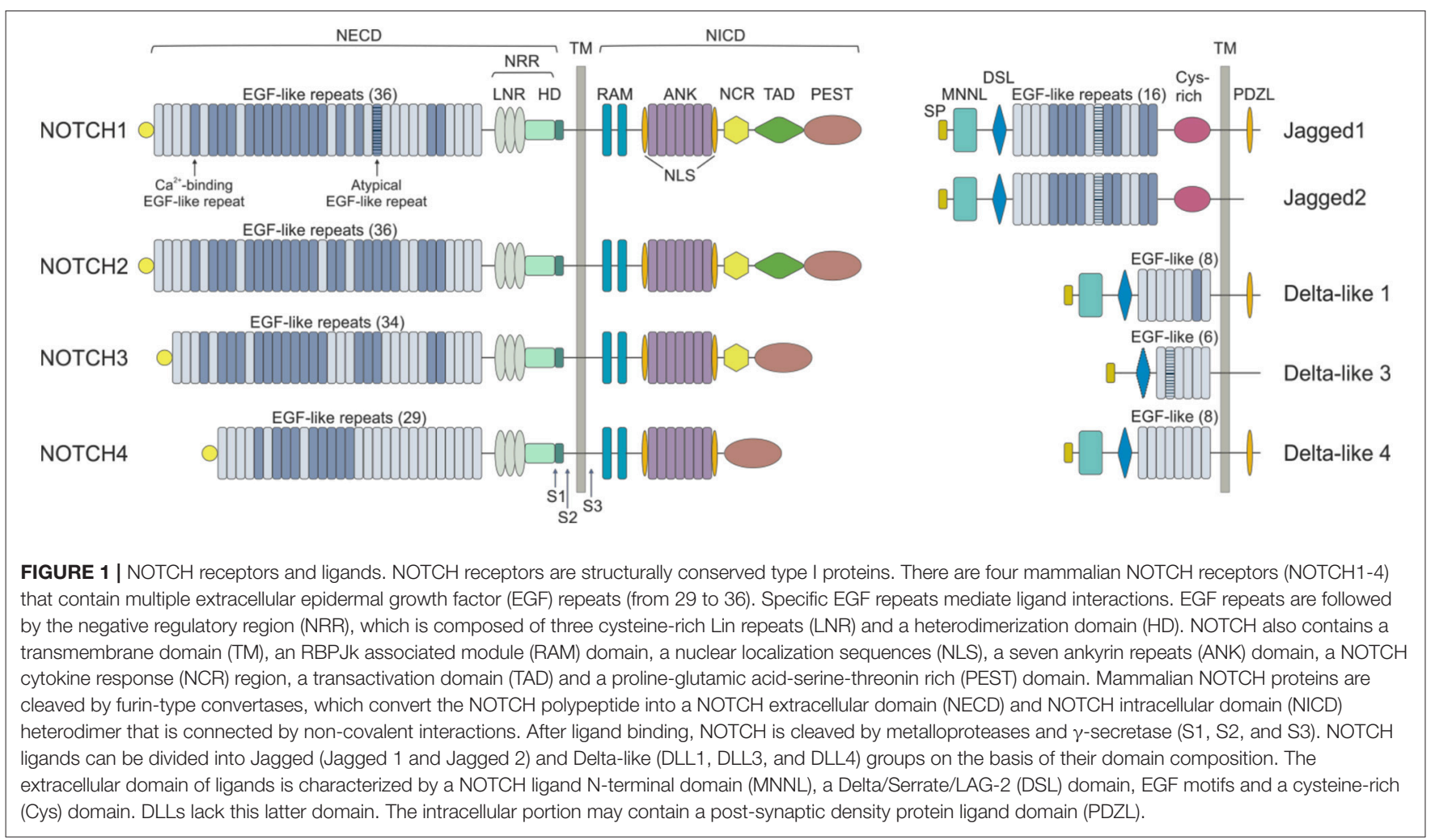

as well as in transformed cells. Furthermore, NOTCH activity fosters a self-regulating feedback loop by transcriptionally controlling genes encoding cytoplasmic protein that modulate NICD translocation to the nucleus or binding to RBPJk, such as Deltex1 (DTX1) and NRARP $(27,28)$. Among the genes under a direct NOTCH-dependent transcriptional control, $M Y C$ is an important mediator of NOTCH effects in the transformation process for several tumor types.

Activity of NOTCH signaling is then terminated through the phosphorylation of the PEST domain by cyclin $\mathrm{C} /$ cyclindependent kinase 8 (CDK) 8 and the subsequent ubiquitinylation by the E3 ligase complex, containing the F-box protein FBW7, which drives NICD to proteasome-mediated degradation (29-31) (Figure 2).

\section{NOTCH SIGNALING PARTICIPATES IN B CELL DEVELOPMENT}

In the study of normal immune system, the role of $\mathrm{NOTCH}$ has been mostly characterized in $\mathrm{T}$ cell development, where it regulates $\mathrm{T}$ cell commitment of common lymphoid progenitors (CLPs) at the expenses of $\mathrm{B}$ cell differentiation (32). B lymphopoiesis takes place in the bone marrow (BM) where newly formed B cells are generated from CLPs, before branching into a B1 subset or continuing toward pro-B cells. The former gives rise to long-lived lymphocytes, predominantly found during fetal and neonatal life, and residing in the peritoneal and pleural cavities in adults, where they complete their differentiation into IgM-producing plasma cells (33). On the contrary, pro-B cells differentiate to immature B lymphocytes that migrate to the spleen as transitional type 1 (T1) B cells, then developing into type 2 transitional B cells (T2). T2 lymphocytes can further differentiate in mature B2 cells, which represent the predominant B population in adult secondary lymphoid organs and the main effectors of adaptive immunity. Following specific microenvironmental signals, they differentiate in two main subsets in a T cell-independent or -dependent way, respectively: (i) marginal zone (MZ) B lymphocytes, residing exclusively in the spleen, and (ii) follicular (FO) B cells that can circulate and are more widely distributed in splenic and lymph node (LN) follicles, as well as in the BM, and can participate in germinal center (GC) reaction (34).

The expression and functions of $\mathrm{NOTCH}$ components in normal B cell biology has so far proven controversial for many aspects, likely because these proteins show distinct roles in early $v s$. late phases of B cell development and when considering fetal or adult B cell generation. For instance, in a study performed on human fetal B cells, Bertrand and colleagues showed that NOTCH1 mRNA and proteins are expressed, throughout normal B cell development, whereas NOTCH2 expression is limited to late pre-B cells expressing low levels of surface immunoglobulin. The authors hypothesized that, given its ubiquitous expression in B cell development, NOTCH1 could modulate proliferation and B cell differentiation through multiple developmental checkpoints (35). In contrast to these observations, other studies examining adult murine $\mathrm{B}$ cell subsets, described a modulation of NOTCH components through B cell development, with NOTCH1 and NOTCH3 being highly 


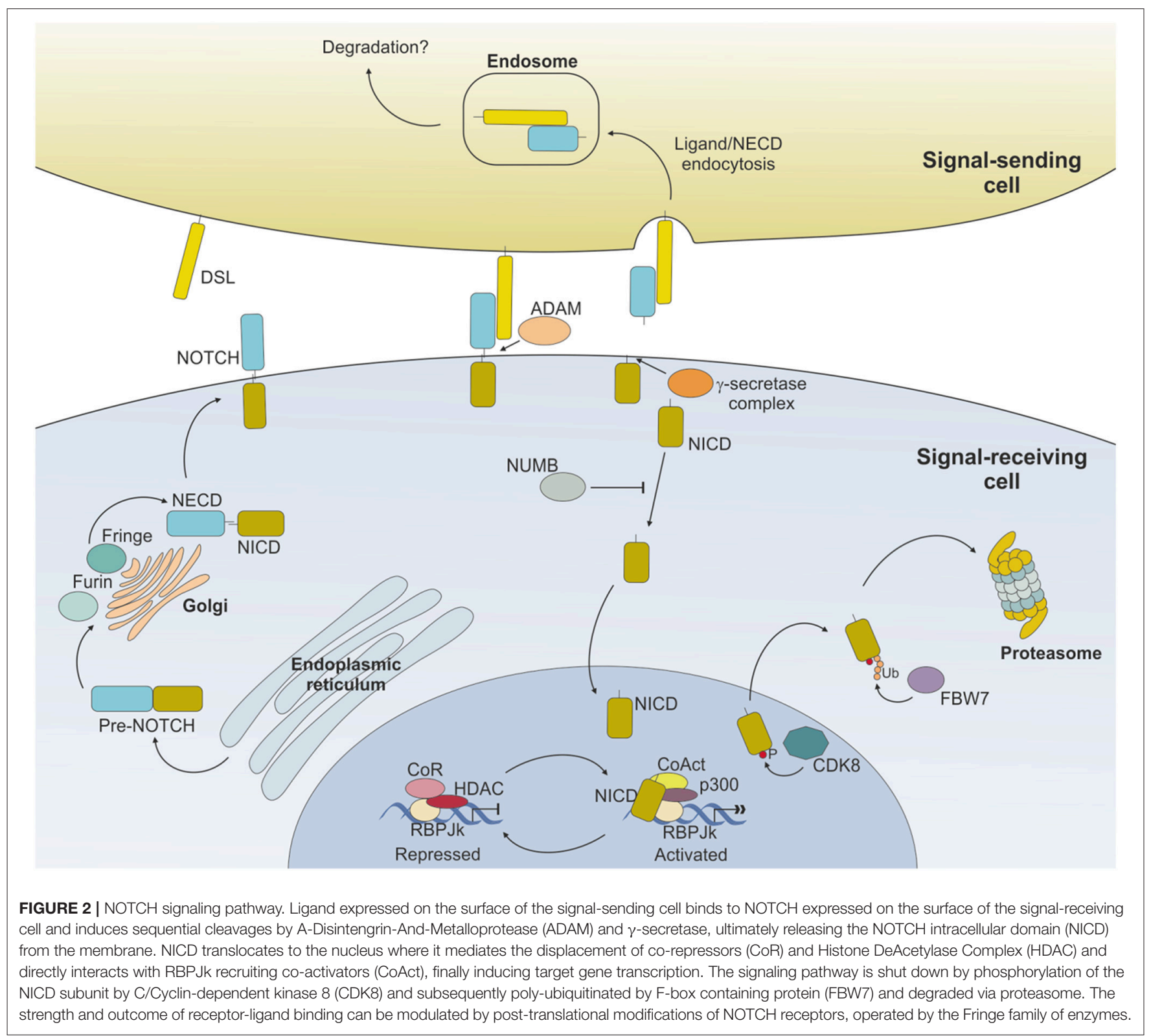

expressed in pro-B cells, progressively decreasing in pre- and immature B cells and maintaining low levels in peripheral B cells. At variance, $\mathrm{NOTCH} 2$ transcript was progressively upregulated with sustained expression in peripheral B cells (36).

Ligands belonging to both DLL and Jagged families are expressed on the surface of a wide range of BM stromal cells and can exert different effects on signal-receiving cells depending on the differentiation status of $\mathrm{B}$ cell progenitors and the cooperation with accessory stimuli present in the niches (37). Importantly, their expression is discontinuous, turning NOTCH signaling on or off according to developmental needs. B cell development is driven by specific cytokines such as CXCL12 in the earliest phases and interleukin (IL)-7 as differentiation proceeds (38). Early B cell progenitors such as prepro $\mathrm{B}$ cells reside in microenvironmental niches where CXCL12 is expressed, while NOTCH ligands are not. In fact, CLPs commitment to the B cell lineage requires NOTCH signaling shut down, at variance with $\mathrm{T}$ cell development, which is strictly dependent on NOTCH1 expression (39). As development proceeds, B cell precursors migrate from CXCL12- to IL-7expressing stroma, an environment where both DLL and Jagged ligands are expressed, suggesting that NOTCH signaling may have a role in committed B cells developing in the BM and ready to migrate toward secondary lymphoid niches to complete the differentiation process $(37,40)$.

Furthermore, beside BM stroma, developing B cells can themselves surface express NOTCH ligands, thereby suggesting that $\mathrm{NOTCH}$ signaling can operate through multiple cellular interactions, other than stromal cells. Indeed, Bertrand and colleagues observed that Jagged-1 is mainly expressed by BM 
stromal cells whereas Delta-like ligands are preferentially expressed in pro-B and pre-B cells, hypothesizing different outcomes of $\mathrm{NOTCH}$ signaling according to different ligand binding. They suggested that NOTCH-DLL interactions occurring between $\mathrm{B}$ cell precursors with equivalent developmental potential (termed "lateral signaling"), may contribute to the maintenance of a normal B lineage homeostasis, by signaling some cells to commit to a specific differentiation fate, while maintaining others in the original precursor state (35).

While the impact of $\mathrm{NOTCH}$ signaling in early $\mathrm{B}$ cell development is still controversial and only partially clarified, its role later on in the differentiation process is better documented. For example, conditional knock out of $\mathrm{NOTCH} 2$ in murine $\mathrm{B}$ cells results in the complete absence of MZ B cells, without affecting other B cell subsets, and in increased mortality due to blood-borne bacterial infections $(36,41)$. Expression of NOTCH2 is thus essential to drive B cells toward MZ maturation. Furthermore, NOTCH ligands show partially overlapping expression patterns in the spleen, with preferential association with vascular stromal cells. Specifically, stromal cells within the MZ strongly express DLL1, which is needed for complete MZ B cell development $(42,43)$.

Together with MZ cells, B1 lymphocytes are considered innate-like lymphocytes showing an antibody repertoire to recognize pathogen-associated molecular patterns. B1 cells can originate from early lymphoid progenitors and CLPs but not from pro-B cells, indicating that cell fate of $\mathrm{B}$ progenitors becomes restricted as soon as cells show commitment toward a specific B lineage (44). Similar to B2 $\mathrm{MZ}$ differentiation, NOTCH2 signaling takes part in $\mathrm{B} 1$ cells development and maintenance. As shown in a study by Witt and colleagues, NOTCH2 haploinsufficiency resulted in reduced B1 B cells in the peritoneal cavity compared to wild-type mice (45). Interestingly, the same group also showed that, at variance with NOTCH1 activation in CLPs that drives $\mathrm{T}$ cell commitment, ectopic induction of NOTCH2 signaling, obtained by transducing BM cells with the activated intracellular domain of NOTCH2 (ICN2), boosted early B cell development and $\mathrm{B} 1$ commitment while blocking B2 progression at the pre-B stage (46). These observations suggest that, despite the strong similarities in signaling components, activation of $\mathrm{NOTCH}$ pathway plays a critical role in lymphocyte development showing distinct non-redundant functions (Figure 3).

Finally, NOTCH signaling also contributes to B cell activation and terminal differentiation to antibody-secreting cells (ASCs) by acting synergistically with B cell receptor (BCR) pathway and co-stimulatory signals such as CD40 or BAFF. The outcome for $B$ cells is increased cell survival and proliferation, along with activation and antibody production $(47,48)$.

Given the multiple implications of NOTCH signaling in B cell development, it is perhaps not surprising that alterations of pathway activity are associated with B cell malignancies. The following paragraphs of this review will focus on the deregulation of NOTCH pathway in various models of B cell neoplasia, starting from chronic lymphocytic leukemia where the biological meaning of this pathway in the pathophysiology of the disease is better characterized than in other B cell malignancies.

\section{NOTCH1 IS ABERRANTLY ACTIVATED IN CHRONIC LYMPHOCYTIC LEUKEMIA (CLL)}

Among B cell malignancies, CLL represents the most frequent adult leukemia with an incidence rate of $\sim 3.9 / 100,000 /$ year (49). It is characterized by the progressive accumulation of maturelooking $\mathrm{CD}^{+} / \mathrm{CD} 23^{+} \mathrm{B}$ lymphocytes in the peripheral blood (PB) with infiltration of lymphoid tissues such as spleen and LNs (50). Clinically, disease course is highly heterogeneous in terms of presentation, outcome and therapy responses, with patients either showing an indolent disease with a limited impact on life expectancy or exhibiting a rapidly progressive disease despite early treatment initiation.

To simplify, this largely depends on the B cell precursor CLL originates from, which is driven by antigen-mediated triggering of BCR together with multiple accessory signals, provided by cell-bound and soluble factors, that reinforce survival and proliferative advantage of leukemic cells $(51,52)$. Among others, CLL cells show overexpression and aberrant activation of NOTCH1 $(53,54)$, and this is markedly evident in lymphoid niches (55), likely due to the fact that stromal cells in the BM and in LNs strongly express NOTCH ligands $(56,57)$. Leukemic cells themselves express NOTCH ligands on the surface, suggesting the existence of autologous signaling (57). Increased activity of NOTCH1 pathway protects leukemic cells from apoptosis through multiple mechanisms, among which the crosstalk with NF- $\kappa \mathrm{B}$ signaling represents a key feature in CLL biology, as it directly regulates expression of anti-apoptotic genes (e.g., c-IAP2 and XIAP) and surface molecules (e.g., CD49d) that facilitate interactions with microenvironment, feeding a proleukemic loop (58) (Figure 4). Moreover, NOTCH1 promotes CLL cell growth and active proliferation by upregulating genes related to ribosome biogenesis and protein translation such as NPM1 and ribosomal proteins (RNPs) (59). Even if a formal demonstration is still missing, these effects are likely mediated through the up-regulation of MYC, as also supported by the involvement of a NOTCH1-MYC axis in the glycolytic switch induced in CLL cells by stromal cells, an event contributing to stroma-mediated chemoresistance (60). Finally, NOTCH1 transcriptional activity in CLL upregulates genes insisting on BCR and cytokine/chemokine signaling, therefore further sustaining leukemic cell survival and proliferation possibly amplifying BCR-mediated effects through a synergistic cooperation $(48,54)$ (Figure 4).

A further indication underlining the importance of NOTCH1 signaling in CLL comes from the finding that mutations in this gene have emerged as one of the most frequent single gene alterations found in CLL at diagnosis (5-15\% of cases) (61). Prevalence increases to $\sim 20 \%$ when considering chemorefractory patients, and up to $\sim 30 \%$ in CLL transforming to aggressive lymphoma (Richter Syndrome, discussed below) (62). The 


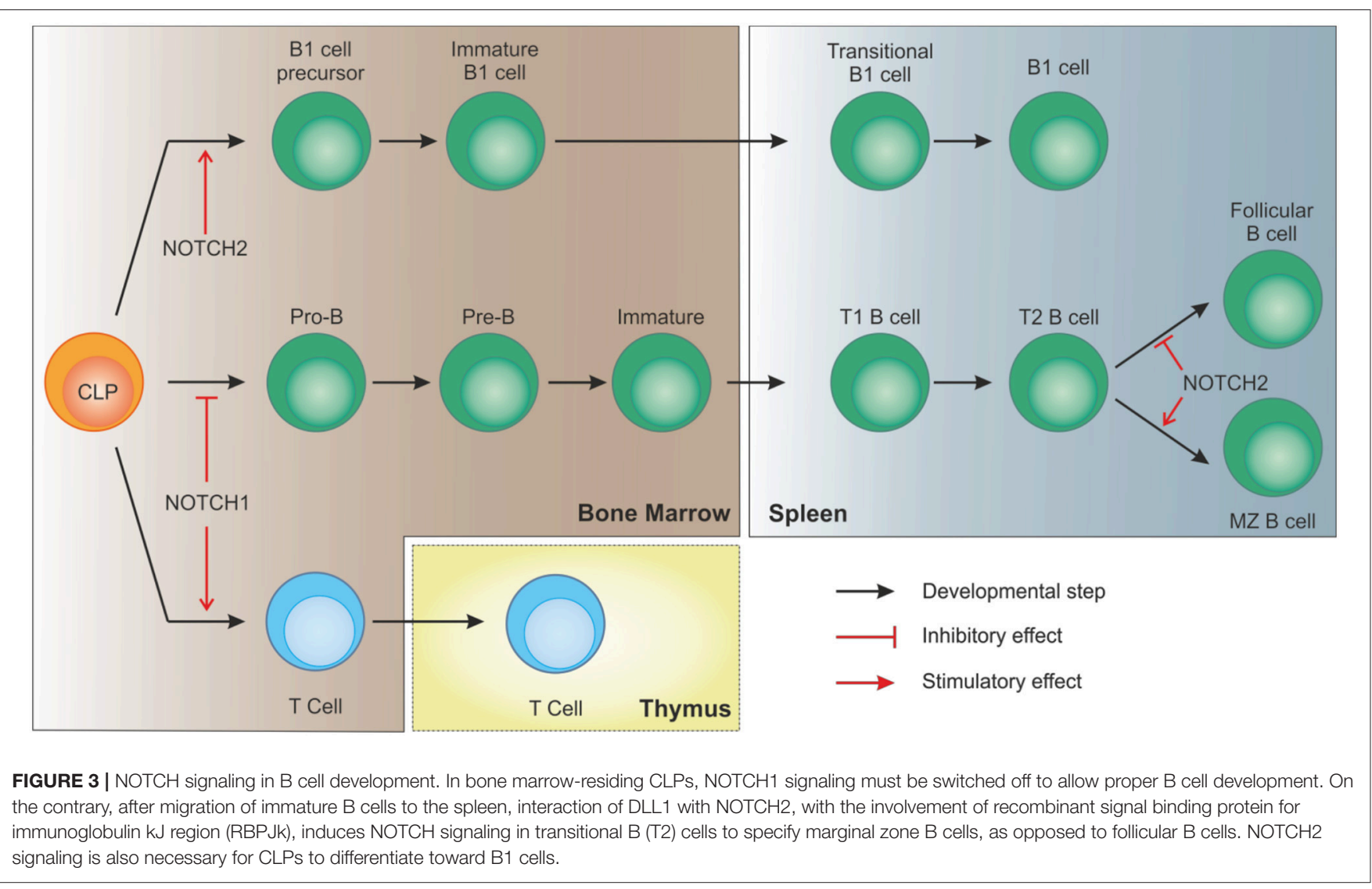

majority of NOTCH1 mutations in CLL occurs within the last exon of the gene and affects the C-terminal portion of the receptor. Specifically, the mutation accounting for $\sim 80 \%$ of cases is a 2-bp deletion in exon 34 that shifts the reading frame (c7541_7542delCT) and generates a premature stop codon (P2514fs*4), truncating the PEST domain (61-63). Frameshift mutations affecting different nucleotides in exon 34 (64), as well as mutations in the non-coding $3^{\prime}$ untranslated region $\left(3^{\prime}\right.$ UTR) of NOTCH1, favoring alternative splicing events with a cryptic donor site in exon 34 (65), have also been described with similar effects on the protein. Mechanistically, PEST domain truncation leads to the loss of the degron domains that direct NOTCH1 to proteasomal degradation, therefore affecting the physiological turnover of NICD, increasing its stability and prolonging pathway activity (66). At variance with T-ALL where mutations in NOTCH1 HD facilitate ligand-independent activation (67), triggering of NOTCH1 signaling in CLL strictly relies on the interaction with the ligand(s), even in the presence of PEST mutations, as these lesions result in the stabilization of ligand-triggered cleaved NOTCH1 rather than in autonomous signaling activation (57).

Clinically, NOTCH1 mutations identify patients with a worse prognosis in terms of therapy responses and with higher risk of disease transformation into an aggressive lymphoma (68). NOTCH1-mutated samples are enriched in chemorefractory CLL and in vitro evidence shows a marked resistance to fludarabine-induced apoptosis, which can be rescued by NOTCH1 inhibitors $(57,69)$. More recently, an association between NOTCH1 mutations and reduced benefits from antiCD20-based chemoimmunotherapy regimens was described (70), likely as a consequence of downmodulation of surface CD20 in this patient subset compared to WT samples (71). From the biological standpoint, reduced CD20 expression is due to the fact that accumulation of mutated NICD in the nucleus perturbs a delicate balance between nuclear interactors, ultimately impacting on the amount of free HDAC that can bind to and silence other genomic regions, including the CD20 promoter (71). Understanding this mechanism prompted the idea that NOTCH1 may exert its effects not only through a direct transcriptional regulation of gene expression, but also indirectly, by altering epigenetic regulation. We recently demonstrated that NOTCH1-mutated cells have an increased migratory potential in response to chemokines that regulate homing of CLL cells to lymphoid niches, such as CCL19, because of a higher expression of the chemokine receptor CCR7. The underlying mechanism is that free HDAC, displaced from the RBPJk-tethered complex by an excess of NICD, can interact with and stabilize DNMT3A, which in turn suppresses the expression of the tumor suppressor gene DUSP22. Loss of DUSP22 phosphatase activity leads to aberrant activation of MAPK and STAT3 signaling, both crucial in CLL homeostasis as downstream players of growth and chemokine receptors, and consequently to a STAT3-dependent 


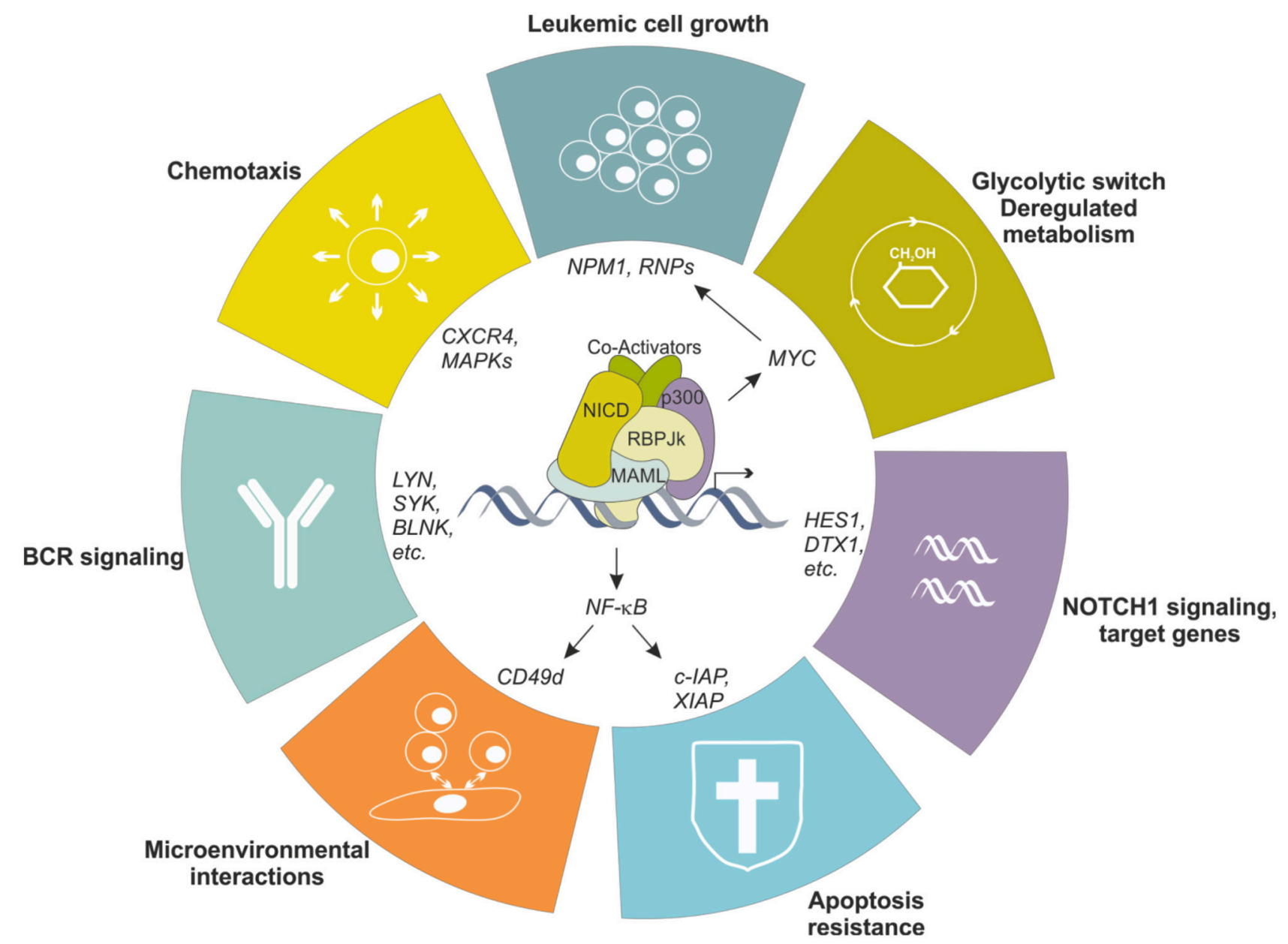

FIGURE 4 | NOTCH1 transcriptional effects in CLL cells. NOTCH1 signaling is aberrantly activated in CLL cells, resulting in transcriptional regulation of several genes, in turn impacting different biological aspects of the neoplastic cells. Increased NOTCH1 activity contributes to leukemic cell growth, protection from apoptosis, metabolic switching toward a glycolytic metabolism, increased migration in response to specific chemokines and facilitates interactions with microenvironment. Moreover, it upregulates several genes encoding proteins insisting on the BCR signaling pathway, the driving force for CLL cells.

upregulation of CCR7 expression and responsiveness (66). Conceivably, NOTCH1-mutated CLL cells may be more prone to reach privileged lymphoid niches that provide pro-leukemic stimuli including NOTCH1 ligands, thereby further fueling pathway activation.

At diagnosis, NOTCH1 mutations can be found either as a clonal defect, present in the large majority of leukemic population, or at the subclonal level (cut-off of Variance Allele Frequency $<12 \%$ ), suggesting that they might be acquired at different steps during CLL development. Specifically, clonally represented mutations are indicative of an early event, whereas subclonal mutations are thought to be acquired later and to be progressively selected. In favor of the view that the acquisition of NOTCH1 mutations is a relatively late event, is the observation that they might be subsequent to at least one driver alteration such as a chromosomal aberration. Accordingly, NOTCH1 mutations are strongly associated with trisomy 12 (72). On the other hand, NOTCH1 mutated subclones have been detected in high-count monoclonal B lymphocytosis (MBL), considered a pre-malignant state potentially evolving to $\operatorname{CLL}(73,74)$. In line with the idea that NOTCH1 alterations may be involved in CLL initiation, several papers revealed the presence of NOTCH1 mutations in early hematopoietic progenitors of CLL patients harboring the defect at the time of disease presentation (75, 76). From the clinical standpoint, the prognostic impact of a low NOTCH1 mutated burden, as well as the evolution of the mutated CLL clone during disease progression, remains unclear. Some studies reported that subclonal NOTCH1 mutations are not associated with chemorefractory disease and remain stable through the follow-up of the disease, suggesting that they may not confer growth advantage to leukemic cells over WT cells, thereby not being prognosticators of aggressive/progressive CLL $(77,78)$. In contrast, other groups observed that CLL patients harboring NOTCH1 mutations in a small portion of the leukemic population show a shorter time to first treatment and reduced overall survival similar to that of clonally mutated 
CLL $(72,79)$. Discrepancies in clinical observations may be due to differences in the cohorts under examination. In the sample cohort investigated by Rasi and colleagues, NOTCH1 mutations were mainly present already at the clonal level, with only few patients showing a mutated fraction below the limit of Sanger sensitivity, likely not fully recapitulating the dynamics of disease evolution in which subclonal NOTCH1 mutations might be implicated (78).

Independently of whether aberrant NOTCH1 signaling is the result of genetic alterations or of a permissive environment, this pathway plays a critical role in CLL pathogenesis and progression and could represent a suitable therapeutic target.

\section{DEREGULATED NOTCHs IN MATURE B CELL MALIGNANCIES OTHER THAN CLL}

A role for $\mathrm{NOTCH}$ in tumor development, progression, and drug resistance has also been highlighted in $\mathrm{B}$ cell malignancies other than CLL. For example, NOTCH deregulation was described in HL, BL (80, 81), DLBCL $(82,83)$, and MM $(84,85)$ (Figure 5).

For most of them, the current knowledge derives from the massive unbiased sequencing approaches on large cohorts of samples that highlighted recurrent mutations in genes of the NOTCH pathway, sharing mechanistic effects on the protein and pathway activity. MM represents an exception, as deregulation of NOTCH relies mostly on the overexpression of signaling components. Overall, form the functional standpoint, the role of NOTCH alterations in these B cell malignancies is less well characterized than in CLL. The following sections of this review are intended to explore the expression, genetics and role of $\mathrm{NOTCH}$ family members in these diseases.

\section{Mantle Cell Lymphoma (MCL)}

$\mathrm{MCL}$ is an aggressive mature $\mathrm{CD} 5^{+} / \mathrm{CD} 23^{-} \mathrm{B}$ cell malignancy, arising from naïve pre-germinal center $\mathrm{B}$ cells of the inner mantle zone and accounting for $6-7 \%$ of non-Hodgkin lymphomas (86). The clinical history is highly variable and ranges from indolent forms to a very aggressive disease with a short median survival, frequent relapses and increasing resistance to chemotherapy $(87,88)$. Regarding the pathogenesis, the primary alteration in MCL is the translocation $\mathrm{t}(11 ; 14)(\mathrm{q} 13 ; \mathrm{q} 32)$, that leads to the juxtaposition of the CCDN1 gene with the IGH locus, resulting in cyclin D1 overexpression and constitutive activation with consequent cell cycle deregulation $(89,90)$. Beside this lesion, secondary genetic alterations are needed to induce lymphomagenesis by disrupting additional critical pathways. Several papers described alterations involving $C D K N 2 A, C D K N 2 B, T P 53, R B 1$ resulting in deregulation of MCL cell proliferation (89-92). In order to further understand the biology of MCL, discover novel pathogenic lesions and potentially identify novel targets for therapy, Kridel and colleagues exploited a powerful whole transcriptome shotgun sequencing (RNAseq) approach applied to primary samples and cell lines (93). Along with mutations in genes known to be involved in MCL pathogenesis, they found recurrent mutations in NOTCH1 (12\% for primary samples and $20 \%$ in cell lines), the majority located in exon 34 that encodes the PEST domain, and thus resulting in an abnormally over-activation of NOTCH1 signaling pathway. The mutational pattern (non-sense truncating mutations and small frame-shift indels) and frequency were similar to what described in CLL $(61,62)$. Mutations in NOTCH1 were associated with a shorter overall survival, suggesting a negative prognostic role for NOTCH1 in MCL. Functionally, Kridel and colleagues found that MCL cell lines were sensitive to NOTCH1 inhibition, as indicated by reduced proliferation and induction of apoptosis, as well as by the modulation of a specific gene expression profile (93). In line with these findings, it was recently demonstrated that NOTCH signaling regulates, directly or indirectly through MYC, a gene signature insisting on BCR signaling, RNA metabolism, and chromatin/transcriptional regulation, thus providing a potential basis for the selective drive of NOTCH gain-of-function mutations in MCL (94). These results have broad implications in B cell lymphomagenesis and pave the way for developing novel therapeutic strategies involving the use of NOTCH pathway inhibitors in these cancers.

By using whole-genome and whole-exome sequencing analysis applied to a large cohort of MCL patients, Bea and colleagues reported that also $\mathrm{NOTCH} 2$ mutations are present as an alternative and mutually exclusive phenomenon to NOTCH1 alterations in aggressive tumors with a poor prognosis (95). The mutation pattern is similar to that reported for NOTCH1, with the generation of a premature stop codon within the PEST domain. Accordingly, gene expression analysis highlighted a different profile, with $\mathrm{NOTCH} 2$ mutated cases displaying an up-regulation of genes involved in cell-cycle and metabolic pathways, together with genes directly regulated by $\mathrm{NOTCH} 2$ (95).

\section{Follicular (FL), Hodgkin's (HL), and Burkitt's (BL) Lymphomas}

Mature follicular B cells represent the pool of recirculating peripheral lymphocytes that generate both plasmablasts and memory cells in response to pathogens. FL arises from germinal center B cells blocked in their capacity to differentiate further $(96,97)$. FL is the most common indolent and slowly progressive lymphoma, with a median survival of $10-14$ years $(98,99)$. Histologic transformation to an aggressive lymphoma occurs in $2-3 \%$ of patients/year and it is associated with chemoresistance, progression and increased mortality (100). From the molecular standpoint, FLs are almost universally characterized by the $\mathrm{t}(14 ; 18)(\mathrm{q} 32 ; \mathrm{q} 21)$ translocation which leads to a fusion of $B L C 2$ to regulatory elements of the $I G H$ locus (101). The resulting constitutive overexpression of BCL2 abrogates the default germinal center apoptosis, likely representing an initiating oncogenic "hit." In addition, the use of high-throughput sequencing technologies has been helpful in identifying other recurrently mutated genes that drive transformations (102). They belong to the BCR/NF- $\kappa \mathrm{B}$ signaling, apoptosis, chromatin remodeling and B cell development pathways (103-108). Most of them have been functionally validated exploiting mouse models, confirming their pathophysiological role in FL and leading to the development of a new wave of drugs (109-112). Recently, 


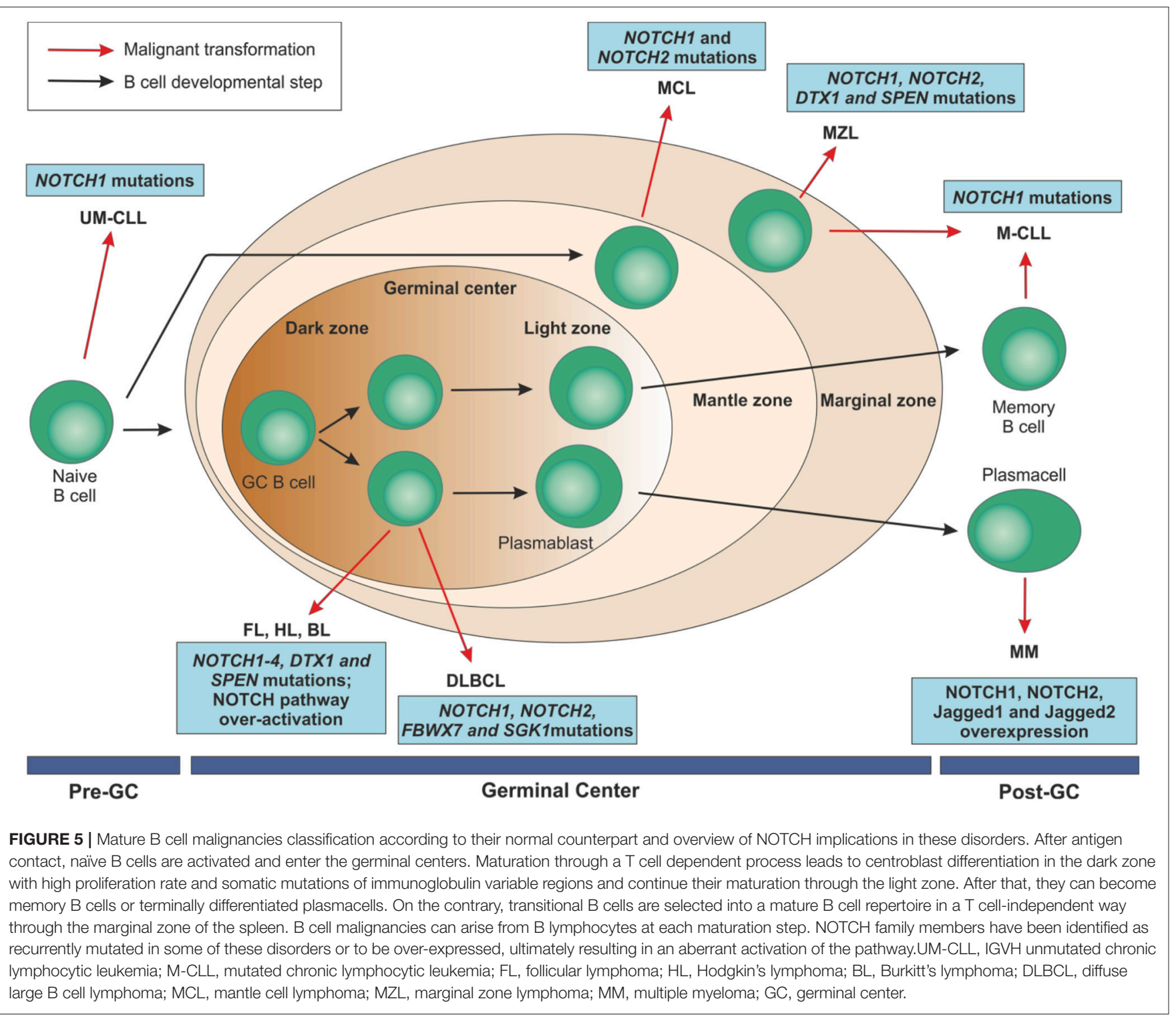

by analyzing a cohort of 112 FL cases by Sanger sequencing, Karube and colleagues reported mutations also in NOTCH1 and $\mathrm{NOTCH} 2$. For the former gene, the only detected mutation was the p.P2514fs*4, with no alterations in the heterodimerization domain. For NOTCH2, a nonsense (p.R2400*) and a frameshift (p.I2304fs*9) mutations were reported (113), resembling the profile found in SMZL (114). All these mutations lead to the truncation of the PEST domain and thus to a persistently active NICD, in line with mechanisms described for other B cell malignancies. Similar results, both in terms of frequency and pattern of mutations, were confirmed in an independent cohort by Krysiak and colleagues (115). These authors found novel mutations in NOTCH3 (4.8\%) and NOTCH4 (4.2\%), as well as in the NOTCH signaling regulators DTX1 (5.7\%) and SPEN (2.9\%).

The finding that genes encoding NOTCH components are altered in subgroups of FLs is in apparent contrast with the physiological role that NOTCH plays in promoting maturation of B cells to MZ (see also Figure 3) $(36,41,116,117)$. On the other hand, a recent paper pointed out that NOTCH2 downmodulation is essential for FL cell survival, calling back into question the significance of NOTCH signaling in this disease (118), and suggesting that more work is needed to solve this apparent controversy.

Overall, these findings highlight the $\mathrm{NOTCH}$ pathway as heavily mutated in this disease, but leave open its functional role.

Overactivation of NOTCH signaling pathway has been reported also in Hodgkin's and Burkitt's lymphomas, both deriving from germinal center B cells. In the former case, tumor cells are characterized by a higher expression of NOTCH1, NOTCH2 and Jagged2, but also of Mastermind-like 2 (MAML2), an essential NOTCH co-activator (119). The final result is an over-activation of $\mathrm{NOTCH}$ signaling pathway as an alternative 
mechanism to the cell-autonomous NOTCH activity, typical of these cancer cells, as shown by the gene-expression profile studies (120). The critical role played by this pathway is underlined by the evidence that targeting of MAML proteins resulted in inhibition of NOTCH and in a reduced proliferation and growth of HL cells (119). It has also been reported that NOTCH activation can trigger NF-kB signaling, promoting survival of HL cells in cooperation with the Epstein-Barr virus (EBV) (121).

A synergistic mechanism between $\mathrm{NOTCH}$ and another partner has been suggested also in $\mathrm{BL}$, where the counterpart is represented by the $\mathrm{BCR}$, with $\mathrm{c}$-myc as potential point of convergence. This cross-talk results in the modulation of proliferation and apoptosis of lymphoma cells and can be reverted by using a gamma-secretase inhibitor (80). More recently, Cao and colleagues, highlighted that specific elements present in the vascular niche contribute to the modulation of NOTCH ligand expression, specifically Jagged1, on endothelial cells that in turns activates $\mathrm{NOTCH} 2$ signaling in $\mathrm{BL}$ cells, enforcing their aggressiveness in terms of extra-nodal invasion and chemoresistance (122).

\section{Diffuse Large B Cell Lymphoma (DLBCL) and Richter Syndrome (RS)}

DLBCL is a highly heterogeneous neoplasm category (123), accounting for $30-40 \%$ of newly diagnosed non-Hodgkin lymphomas (NHL) (124).

Historically, DLBCL was thought to involve recurrent translocations of the $I G H$ gene and the deregulation of rearranged oncogenes, including BCL2, BCL6, or MYC. More recently, the molecular heterogeneity of DLBCLs has been deciphered by gene expression profiling, allowing the classification into two main molecular subtypes: the germinal center B cell like (GCB) and the activated B cell like (ABC). These subtypes arise from distinct $B$ cells at separate stages of differentiation and maturation (125), leading to well-defined gene expression profiles and different clinical outcomes and responses to immunochemotherapy, with $\mathrm{ABC}$ type being the most aggressive and characterized by a poor clinical outcome $(126,127)$.

The most frequently ( $\geq 10 \%$ of all samples) mutated genes in DLBCL belong to pathways controlling cell cycle, DNA damage response, chromatin remodeling, BCR and TLR signaling (125, 128-133) Additional genes were found to be mutated in a lower percentage of samples, but potentially relevant to DLBCL biology, including genes belonging to the NOTCH family.

Very recently, a comprehensive analysis of 304 primary DLBCLs samples integrated low-frequency alterations, recurrent mutations, somatic copy number alterations, and structural variants, to identify five groups of patients with outcomeassociated coordinated genetic signatures, three of which previously undescribed. PEST mutations in NOTCH2 and truncating alterations of its negative regulator SPEN, together with BCL6 structural variants and mutations of the NF$\mathrm{kB}$ pathway were associated to the Cluster 1 (C1) DLBCLs. This subset is characterized by an increased transcriptional abundance of NOTCH2 and BCL6 target genes, as highlighted by gene set enrichment analysis (GSEA). The majority of $\mathrm{C} 1$ DLBCL were classified as ABC-type tumors, by transcriptional profiling. This novel classification may help tailor treatment strategies in these genetically distinct DLBCL subsets (134, 135). These results built on previous findings obtained in large cohorts of lymphoma samples describing mutations in NOTCH pathway as a recurrent defect in DLBCL $(83,136-$ 138). Although belonging to this lymphoma category, RS is considered a distinct subset of DLBCL, as it evolves from a preexisting CLL undergoing a transformation into an aggressive lymphoma in the $10-12 \%$ of cases $(123,139)$. Analysis of IGH rearrangements indicate whether RS is clonally related or unrelated to CLL, thus if it derives from the same B cell clone or if it arises as a secondary independent neoplasia (140). This distinction is clinically relevant as clonally-related RS patients are characterized by a poorer outcome, with no response to standard therapy and with a shorter overall survival compared to clonally unrelated samples (140-142). Whole exome sequencing (WES) and copy-number analyses indicate that inactivation of the TP53 tumor suppressor gene and/or 17p13 deletion represent the most common genetic lesion, observed in $\sim 60 \%$ of patients, while disruption of $C D K N 2 A / B$, a cell cycle regulator, is observed in about $30 \%$ of cases $(140,143,144)$. Other frequent genetic lesions are represented by NOTCH1 and MYC activating events, present in $\sim 30 \%$ of RS cases $(62,140)$, and are mutually exclusive, consistent with the hypothesis that NOTCH1 is a transcriptional activator of MYC (145). Mutations reported for NOTCH1 mainly affect the PEST domain, with the P2514fs* 4 truncating mutation being the most frequent. This event results in the constitutive activation of the pathway as inferred by the presence of the NICD protein and high expression levels of NOTCH1 target genes (146). However, additional functional studies are needed to understand whether this pathway plays a key role as a transforming event from CLL to RS or if it simply contributes to RS aggressiveness. In addition, a combination of germline genetic characteristics, such as polymorphisms in BCL2, LRP4 (147) and CD38 (148) genes, as well as biological features of CLL cells, including unmutated IGVH genes, Zap-70 and CD49d expression, represent risk factors for disease development (149).

\section{Marginal Zone Lymphoma (MZL)}

MZLs, accounting for 5-17\% of all non-Hodgkin's lymphomas, derive from $\mathrm{B}$ cells of the "marginal zone," the external part of the secondary lymphoid follicles. The MZ is more evident in the lymphatic tissues continuously exposed to external antigens, such as the mesenteric lymph nodes, the mucosa-associated lymphoid tissues (MALT), and the spleen. MZ B cells act as innate-like lymphocytes able to mount rapid antibody responses mostly to T cell-independent antigens (150).

There are three different MZL entities with specific diagnostic criteria, clinical behavior, and therapeutic implications: the extranodal MZL of mucosa-associated lymphoid tissue (MALT) type (MALT lymphoma), the splenic MZL (SMZL), and the nodal MZL (NMZL) (151).

Despite specific alterations peculiar of each subtype, there are genetic lesions and deregulated pathways that are shared (108, 152, 153). Trisomies of chromosomes 3 and 18 and deletion at 
$6 \mathrm{q} 23$ are frequent events in all MZLs, as well as somatic mutations of genes coding for proteins involved in chromatin remodeling $(114,154-156)$. NF-kB and NOTCH are among the pathways that are recurrently mutated in MZLs, (114, 155, 157-160).

MALT lymphoma is the most common MZL type, accounting for 5-8\% of all B cell lymphomas (161). It arises from lymphoid populations that are induced by chronic inflammation in extranodal sites. The most frequently affected organ is the stomach, with MALT lymphomas associated to chronic gastritis (162). Beside infections, chronic inflammations caused by autoimmune diseases are risk factors for the development of MALT lymphoma (163). Using targeted sequencing approaches, mutation in NOTCH1 (8\%) and NOTCH2 (8\%) genes have been recently reported (154). Most of the aberrations are frameshift indels and non-sense mutations, clustering in the C-terminal portion of the molecule and specifically in the TAD and PEST domains, in line with mutations and functional effects observed in CLL, MCL, and SMZL. A similar pattern of mutations in NOTCH2 has been identified through WES/whole-genome sequencing (WGS) studies in SMZL and NMZL, with percentages varying from 10 to $25 \%$ in SMZL and $25 \%$ in NMZL (164).

SMZL is a neoplasm of mature B cells that involves spleen, $\mathrm{BM}$, and $\mathrm{PB}$. Within the spleen, tumor cells are represented by small lymphocytes that occupy the MZ surrounding germinal centers and infiltrate the red pulp (123). In SMZL, mutations of $\mathrm{NOTCH} 2$, together with genes encoding $\mathrm{NOTCH}$ signaling pathway components, represent the most recurrent genetic lesions, remarking upon deregulated proliferation and migration as the most affected pathways (114, 165-168). As for MALT lymphomas, most of the identified alterations are frameshift or non-sense mutations clustering within the hotspot region in exon 34, affecting the PEST domain and increasing NOTCH2 activation $(114,169,170)$. The 2-bp deletion (p.P2515fs*4) in NOTCH1, recurrent in CLL $(61,62,171)$ and MCL (93), is observed in a minor percentage of SMZL ( 5\%), (114, 169, 172174). Furthermore, mutations in SPEN and DTX1 are reported in a small percentage (5\%) of SMZL cases (114). The former plays a role in restraining $\mathrm{NOTCH}$ signaling through a physical interaction with and consequent repression of the transcription factor RBPJk $(165,175,176)$. In physiological conditions, SPEN is as a negative regulator of $\mathrm{B}$ lymphocyte differentiation into $\mathrm{MZ}$ B cells counteracting the activity of NOTCH (165). Mutations truncate SPEN C-terminal domain, which is involved in the interaction with RBPJk and is critical for NOTCH signaling activation. DTX1 is highly expressed in MZ B cells and may be relevant for the late steps of $\mathrm{B}$ lymphocyte differentiation $(36,177)$. It encodes a RING finger ubiquitin ligase that binds NOTCH family members, modulating their signaling activity. In SMZL, mutations map within two distinct functional domains of DTX1, involved in protein interactions (114). Of note, mutations in genes encoding $\mathrm{NOTCH}$ signaling components appear to be largely mutually exclusive with an overall rate of mutations of the pathway in SMZL of 32\%.

NMZL is a rare and indolent B cell tumor that differs from SMZL in terms of pattern of dissemination, being primarily a nodal B cell cancer without clinical evidence of extranodal or splenic disease $(123,178)$. In general, the mutational profile of
NMZL is quite similar to that of SMZL, as revealed by WES studies (179). Specifically, NOTCH signaling pathway appears to be mutated mainly in NOTCH2 (20\%), SPEN (11\%), and RBPJL (6\%) (179).

\section{Multiple Myeloma (MM)}

In the last decade, several studies have highlighted a role for the NOTCH pathway in MM, a tumor characterized by the proliferation of BM post-GC plasma cells, with release of monoclonal antibodies in blood (180). From the pathological standpoint, MM is characterized by profound genomic instability, epigenetic alterations and strongly dependent on the interaction with the microenvironment (181-184). Indeed, MM cells localization in the BM milieu allows direct interactions between tumor and non-tumor cells residing in the BM, via adhesion molecules and soluble factors, which promote neoplastic cell growth, survival, bone disease, acquisition of drug resistance, and consequent disease relapse. Cumulative evidence indicates a key role of $\mathrm{NOTCH}$ signaling in $\mathrm{MM}$ onset and progression (185-188).

Unlike other NOTCH-related malignancies, where the majority of patients carry gain-of-function mutations in pathway members, in MM cells NOTCH signaling is aberrantly activated due to increased expression of both receptors and ligands $(185,186)$. In physiological conditions, hematopoietic stem cells express $\mathrm{NOTCH}$ receptors receiving signals from ligands expressed by BM stromal cells. This mechanism contributes to stem cell renewal, survival and differentiation. In MM, this interplay is hijacked by tumor cells to enhance their proliferative rate and escape from therapy (189). Moreover, experimental evidence indicates that $\mathrm{NOTCH}$ signaling directly regulates the expression and function of CXCR4, thereby controlling trafficking of MM cells toward BM niches, a mechanism similar to that described in CLL (190).

Several independent studies report the overexpression of NOTCH1 and 2 and the two ligands Jagged1 and Jagged2 by MM cells $(185,186,191,192)$ during disease progression. Indeed, increased NOTCH1 and Jagged1 expression parallels the transition from monoclonal gammopathy of undertermined significance (MGUS) to MM (186), while NOTCH2 expression is increased in more aggressive subsets of patients, carrying specific translocations (193). Of note, most of the genes belonging to the $\mathrm{NOTCH}$ signaling pathway are located on chromosomes found to be numerically altered in selected subtypes of MM (9).

Notably, the overexpression of the "NOTCH network" also results in the activation of NOTCH signaling in surrounding stromal cells, contributing to myeloma cell proliferation, survival, and migration, as well as to bone disease and intrinsic and acquired pharmacological resistance. This "backward signaling" occurs as a consequence of activation of NOTCH receptors on BM stromal cells by ligands expressed by MM cells. This interaction results in a NOTCH-mediated upregulation of IL6 secretion by BM stromal cells, one of the most important growth and survival factors for MM cells (188). The existence of a bidirectional NOTCH signaling offers novel hints in the study of B cell malignancies, and opens new perspectives in the therapeutic scenario. 


\section{IS NOTCH DRUGGABLE IN B CELL MALIGNANCIES?}

Independently of the mutational status, NOTCH signaling activation is tightly regulated at multiple steps, thereby providing different strategies to therapeutically target this pathway. In a top-down view, we can envisage at least three levels of intervention: (i) in the extracellular space, interrupting receptor/ligand interactions with specific blocking antibodies; (ii) at the membrane level, preventing the enzymatic cleavages critical for NOTCH activation; and (iii) inside the cells, exploiting selective inhibitors of the "NOTCH interactome."

Given the widespread involvement of this molecular family in cancer, the NOTCH "drug market" has rapidly grown with the development of antibodies or inhibitors, tested in multiple clinical trials, particularly in the context of solid tumors and T-ALL, with only studies in B cell malignancies $(9,194)$.

Initial results using $\gamma$-secretase inhibitors (GSI) demonstrated excessive toxicity, particularly at the gastrointestinal levels, mainly due on one side to off-target effects and on the other side to the simultaneous targeting of all $\mathrm{NOTCH}$ isoforms, expressed on several tissues, thus interfering also with the physiological role of this pathway. The introduction of different schemes of administration, the combination with steroids and the design of more selective inhibitors and drugs have partly overcome these side effects, attaining promising therapeutic responses. In line with the aim of increasing treatment specificity while minimizing toxicity, monoclonal antibodies, specifically binding single members of the NOTCH family, were designed as an alternative approach (195). However, these reagents have not yet reached clinical trials in B-cell malignancies.

An alternative to GSI approaches is immunotherapy, based on the use of blocking antibodies against NOTCH, Delta/Jagged ligands or other extracellular components involved in the NOTCH signaling cascade. Since these drugs affect selectively a NOTCH family member or ligand, they could potentially show fewer side effects compared to GSI (195-198).

Even if limited results have been obtained in clinical trials for B cell neoplasms, promising evidence for the use of these drugs is coming from in vitro and ex-vivo data obtained in MCL (93) and MM (84). Treatment with GSI resulted in decreased proliferation and increased apoptosis of MCL cell lines, with a concomitant modulation of a selected set of genes strictly dependent on NOTCH. These inhibitors proved to be effective in $\mathrm{MM}$ acting directly on tumor cells by enhancing apoptosis but also preventing the BM stroma-mediated protection of MM cells from drug-induced apoptosis. Furthermore, GSI is able to enhance the cytotoxicity induced by selective chemotherapeutic agents, including doxorubicine (85).

Similar effects of GSI, used alone or in combination with fludarabine, were obtained in the high-risk CLL subset of patients carrying a mutated NOTCH1. These cells proved to be sensitive to PF-03084014, a non-competitive and reversible GSI, with inhibition of the constitutive activation of the pathway and modulation of apoptosis, as well as migration of leukemic cells (69). Further evidence sustaining a combination strategy to target CLL cells was recently obtained by Secchiero and colleagues who reported the ability of GSI to enhance the anti-leukemic activity of ibrutinib, independently of the mutational status of NOTCH1 (199).

Considering that, in hematological B cell malignancies, deregulated NOTCH signaling is ancillary to driver aberrant pathways, a combined therapeutic approach may represent a successful way to target tumor cells.

\section{CONCLUDING REMARKS}

To bear witness of the importance of NOTCH in normal Bcell ontogenesis, mutations in genes belonging to this pathway are invariably found in all mature B cell malignancies. In some instances, the mutational burden insisting on the pathway reaches one third or more of patients, as is the case for MZL or RS. Overall, the emerging picture is that NOTCH signaling is finely tuned in cell- and microenvironment-specific ways. In B cell malignancies, it works primarily as an oncogene, even though functional studies on the mechanisms and consequences of NOTCH signaling are only starting now. Likely, they will allow to improve its therapeutic targeting, also through the design and validation of more selective drugs.

\section{AUTHOR CONTRIBUTIONS}

FA and TV wrote the manuscript and sketched the figures. SD contributed to the writing and editing of the review. All the authors approved the manuscript for its publication.

\section{ACKNOWLEDGMENTS}

This work was supported by the Italian Institute for Genomic Medicine Institutional funds, the Associazione Italiana per la Ricerca sul Cancro (AIRC IG-17314 to SD), by the Cassa di Risparmio di Torino Foundation (Fondazione CRT RF2017.0979 to TV), by the Italian Ministry of Health (GR2011-02346826 to SD and GR-2011-02349282 to TV) and by the Ministry of Education, University and Research-MIUR project Dipartimenti di Eccellenza 2018-2022.

\section{REFERENCES}

1. Campo E, Swerdlow SH, Harris NL, Pileri S, Stein H, Jaffe ES. The 2008 WHO classification of lymphoid neoplasms and beyond: evolving concepts and practical applications. Blood (2011) 117:5019-32. doi: 10.1182/blood-2011-01-293050

2. Shaffer AL III, Young RM, Staudt LM. Pathogenesis of human B cell lymphomas. Ann Rev Immunol. (2012) 30:565-610. doi: 10.1146/annurev-immunol-020711-075027

3. Ghia P, Nadel B, Sander B, Stamatopoulos K, Stevenson FK. Early stages in the ontogeny of small B-cell lymphomas: genetics and microenvironment. $J$ Intern Med. (2017) 282:395-414. doi: 10.1111/joim.12608 
4. Kopan R, Ilagan MX. The canonical Notch signaling pathway: unfolding the activation mechanism. Cell (2009) 137:216-33. doi: 10.1016/j.cell.2009.03.045

5. Tanigaki K, Kuroda K, Han H, Honjo T. Regulation of $B$ cell development by Notch/RBP-J signaling. Semin Immunol. (2003) 15:113-9. doi: 10.1016/S1044-5323(03)00008-3

6. Aster JC, Pear WS, Blacklow SC. The varied roles of Notch in cancer. Ann Rev Pathol. (2017) 12:245-75. doi: 10.1146/annurev-pathol-052016-100127

7. McCarter AC, Wang Q, Chiang M. Notch in Leukemia. Adv Exp Med Biol. (2018) 1066:355-94. doi: 10.1007/978-3-319-89512-3_18

8. Kluk MJ, Ashworth T, Wang H, Knoechel B, Mason EF, Morgan EA, et al. Gauging NOTCH1 activation in cancer using immunohistochemistry. PLoS ONE (2013) 8:e67306. doi: 10.1371/journal.pone.0067306

9. Colombo M, Galletti S, Garavelli S, Platonova N, Paoli A, Basile A, et al. Notch signaling deregulation in multiple myeloma: a rational molecular target. Oncotarget (2015) 6:26826-40. doi: 10.18632/oncotarget.5025

10. Andersson ER, Sandberg R, Lendahl U. Notch signaling: simplicity in design, versatility in function. Development (2011) 138:3593-612. doi: $10.1242 /$ dev. 063610

11. Bray SJ. Notch signalling: a simple pathway becomes complex. Nat Rev Mol Cell Biol. (2006) 7:678-89. doi: 10.1038/nrm2009

12. Cordle J, Redfieldz C, Stacey M, van der Merwe PA, Willis AC, Champion BR, et al. Localization of the delta-like-1-binding site in human Notch-1 and its modulation by calcium affinity. J Biol Chem. (2008) 283:11785-93. doi: $10.1074 /$ jbc.M708424200

13. Gordon WR, Arnett KL, Blacklow SC. The molecular logic of Notch signaling-a structural and biochemical perspective. J Cell Sci. (2008) $121(\mathrm{Pt}$ 19):3109-19. doi: $10.1242 /$ jcs. 035683

14. Stanley P, Okajima T. Roles of glycosylation in Notch signaling. Curr Topics Dev Biol. (2010) 92:131-64. doi: 10.1016/S0070-2153(10)92004-8

15. Hicks C, Johnston SH, diSibio G, Collazo A, Vogt TF, Weinmaster G. Fringe differentially modulates Jagged 1 and Delta1 signalling through Notch1 and Notch2. Nat Cell Biol. (2000) 2:515-20. doi: 10.1038/35019553

16. Brou C, Logeat F, Gupta N, Bessia C, LeBail O, Doedens JR, et al. A novel proteolytic cleavage involved in Notch signaling: the role of the disintegrin-metalloprotease TACE. Mol Cell (2000) 5:207-16. doi: 10.1016/S1097-2765(00)80417-7

17. Gordon WR, Zimmerman B, He L, Miles LJ, Huang J, Tiyanont $\mathrm{K}$, et al. Mechanical allostery: evidence for a force requirement in the proteolytic activation of Notch. Dev Cell (2015) 33:729-36. doi: 10.1016/j.devcel.2015.05.004

18. Schroeter EH, Kisslinger JA, Kopan R. Notch-1 signalling requires ligandinduced proteolytic release of intracellular domain. Nature (1998) 393:382-6. doi: $10.1038 / 30756$

19. Struhl G, Greenwald I. Presenilin is required for activity and nuclear access of Notch in Drosophila. Nature (1999) 398:522-5. doi: 10.1038/19091

20. Hsieh JJ, Hayward SD. Masking of the CBF1/RBPJ kappa transcriptional repression domain by Epstein-Barr virus EBNA2. Science (1995) 268:560-3.

21. Oswald F, Winkler M, Cao Y, Astrahantseff K, Bourteele S, Knochel $\mathrm{W}$, et al. RBP-Jkappa/SHARP recruits CtIP/CtBP corepressors to silence Notch target genes. Mol Cell Biol. (2005) 25:10379-90. doi: 10.1128/MCB.25.23.10379-10390.2005

22. Castel D, Mourikis P, Bartels SJ, Brinkman AB, Tajbakhsh S, Stunnenberg HG. Dynamic binding of RBPJ is determined by Notch signaling status. Genes Dev. (2013) 27:1059-71. doi: 10.1101/gad.211912.112

23. Wu L, Aster JC, Blacklow SC, Lake R, Artavanis-Tsakonas S, Griffin JD. MAML1, a human homologue of Drosophila mastermind, is a transcriptional co-activator for NOTCH receptors. Nat Genet. (2000) 26:484-9. doi: 10.1038/82644

24. Oswald F, Tauber B, Dobner T, Bourteele S, Kostezka U, Adler G, et al. p300 acts as a transcriptional coactivator for mammalian Notch-1. Mol Cell Biol. (2001) 21:7761-74. doi: 10.1128/MCB.21.22.7761-7774.2001

25. Yatim A, Benne C, Sobhian B, Laurent-Chabalier S, Deas O, Judde $\mathrm{JG}$, et al. NOTCH1 nuclear interactome reveals key regulators of its transcriptional activity and oncogenic function. Mol Cell (2012) 48:445-58. doi: 10.1016/j.molcel.2012.08.022
26. Borggrefe T, Oswald F. The Notch signaling pathway: transcriptional regulation at Notch target genes. Cell Mol Life Sci. (2009) 66:1631-46. doi: $10.1007 / \mathrm{s} 00018-009-8668-7$

27. Matsuno K, Eastman D, Mitsiades T, Quinn AM, Carcanciu ML, Ordentlich $\mathrm{P}$, et al. Human deltex is a conserved regulator of Notch signalling. Nat Genet. (1998) 19:74-8. doi: 10.1038/ng0598-74

28. Phng LK, Potente M, Leslie JD, Babbage J, Nyqvist D, Lobov I, et al. Nrarp coordinates endothelial Notch and Wnt signaling to control vessel density in angiogenesis. Dev Cell (2009) 16:70-82. doi: 10.1016/j.devcel.2008.12.009

29. Gupta-Rossi N, Le Bail O, Gonen H, Brou C, Logeat F, Six E, et al. Functional interaction between SEL-10, an F-box protein, and the nuclear form of activated Notch1 receptor. J Biol Chem. (2001) 276:34371-8. doi: 10.1074/jbc.M101343200

30. Oberg C, Li J, Pauley A, Wolf E, Gurney M, Lendahl U. The Notch intracellular domain is ubiquitinated and negatively regulated by the mammalian Sel-10 homolog. J Biol Chem. (2001) 276:35847-53. doi: 10.1074/jbc.M103992200

31. Fryer CJ, White JB, Jones KA. Mastermind recruits CycC:CDK8 to phosphorylate the Notch ICD and coordinate activation with turnover. Mol Cell (2004) 16:509-20. doi: 10.1016/j.molcel.2004.10.014

32. Pui JC, Allman D, Xu L, DeRocco S, Karnell FG, Bakkour S, et al. Notch1 expression in early lymphopoiesis influences B versus $\mathrm{T}$ lineage determination. Immunity (1999) 11:299-308.

33. Cunningham AF, Flores-Langarica A, Bobat S, Dominguez Medina CC, Cook CN, Ross EA, et al. B1b cells recognize protective antigens after natural infection and vaccination. Front Immunol. (2014) 5:535. doi: 10.3389/fimmu.2014.00535

34. Cruickshank MN, Ulgiati D. The role of notch signaling in the development of a normal B-cell repertoire. Immunol Cell Biol. (2010) 88:117-24. doi: $10.1038 /$ icb.2009.73

35. Bertrand FE, Eckfeldt CE, Lysholm AS, LeBien TW. Notch-1 and Notch-2 exhibit unique patterns of expression in human B-lineage cells. Leukemia (2000) 14:2095-102. doi: 10.1038/sj.leu.2401942

36. Saito T, Chiba S, Ichikawa M, Kunisato A, Asai T, Shimizu K, et al. Notch2 is preferentially expressed in mature B cells and indispensable for marginal zone B lineage development. Immunity (2003) 18:675-85. doi: 10.1016/S1074-7613(03)00111-0

37. Tokoyoda K, Egawa T, Sugiyama $\mathrm{T}$, Choi BI, Nagasawa $\mathrm{T}$, Cellular niches controlling B lymphocyte behavior within bone marrow during development. Immunity (2004) 20:707-18. doi: 10.1016/j.immuni.2004.05.001

38. Egawa T, Kawabata K, Kawamoto H, Amada K, Okamoto R, Fujii N, et al. The earliest stages of B cell development require a chemokine stromal cell-derived factor/pre-B cell growth-stimulating factor. Immunity (2001) 15:323-34. doi: 10.1016/S1074-7613(01)00185-6

39. Radtke F, MacDonald HR, Tacchini-Cottier F. Regulation of innate and adaptive immunity by Notch. Nat Rev Immunol. (2013) 13:427-37. doi: $10.1038 /$ nri3445

40. Tanigaki K, Honjo T. Regulation of lymphocyte development by Notch signaling. Nat Immunol. (2007) 8:451-6. doi: 10.1038/ni1453

41. Tanigaki K, Han H, Yamamoto N, Tashiro K, Ikegawa M, Kuroda K, et al. Notch-RBP-J signaling is involved in cell fate determination of marginal zone B cells. Nat Immunol. (2002) 3:443-50. doi: 10.1038/ni793

42. Tan JB, Xu K, Cretegny K, Visan I, Yuan JS, Egan SE, et al. Lunatic and manic fringe cooperatively enhance marginal zone B cell precursor competition for delta-like 1 in splenic endothelial niches. Immunity (2009) 30:254-63. doi: 10.1016/j.immuni.2008.12.016

43. Song Y, Kumar V, Wei HX, Qiu J, Stanley P. Lunatic, manic, and radical fringe each promote T and B cell development. J Immunol. (2016) 196:232-43. doi: 10.4049/jimmunol.1402421

44. Esplin BL, Welner RS, Zhang Q, Borghesi LA, Kincade PW. A differentiation pathway for B1 cells in adult bone marrow. Proc Natl Acad Sci USA. (2009) 106:5773-8. doi: 10.1073/pnas.0811632106

45. Witt CM, Won WJ, Hurez V, Klug CA. Notch2 haploinsufficiency results in diminished B1 B cells and a severe reduction in marginal zone B cells. $J$ Immunol. (2003) 171:2783-8. doi: 10.4049/jimmunol.171.6.2783 
46. Witt CM, Hurez V, Swindle CS, Hamada Y, Klug CA. Activated Notch2 potentiates CD8 lineage maturation and promotes the selective development of B1 B cells. Mol Cell Biol. (2003) 23:8637-50.

47. Santos MA, Sarmento LM, Rebelo M, Doce AA, Maillard I, Dumortier A, et al. Notch1 engagement by Delta-like-1 promotes differentiation of B lymphocytes to antibody-secreting cells. Proc Natl Acad Sci USA. (2007) 104:15454-9. doi: 10.1073/pnas.0702891104

48. Thomas M, Calamito M, Srivastava B, Maillard I, Pear WS, Allman D. Notch activity synergizes with B-cell-receptor and CD40 signaling to enhance B-cell activation. Blood (2007) 109:3342-50. doi: 10.1182/blood-2006-09-046698

49. Hallek M. Chronic lymphocytic leukemia: 2015 Update on diagnosis, risk stratification, and treatment. Am J Hematol. (2015) 90:446-60. doi: 10.1002/ajh.23979

50. Dighiero G, Hamblin TJ. Chronic lymphocytic leukaemia. Lancet (2008) 371:1017-29. doi: 10.1016/S0140-6736(08)60456-0

51. Chiorazzi N, Ferrarini M. Cellular origin(s) of chronic lymphocytic leukemia: cautionary notes and additional considerations and possibilities. Blood (2011) 117:1781-91. doi: 10.1182/blood-2010-07-155663

52. Kipps TJ, Stevenson FK, Wu CJ, Croce CM, Packham G, Wierda WG, et al. Chronic lymphocytic leukaemia. Nat Rev Dis Primers (2017) 3:16096. doi: $10.1038 / \mathrm{nrdp} .2016 .96$

53. Rosati E, Sabatini R, Rampino G, Tabilio A, Di Ianni M, Fettucciari $\mathrm{K}$, et al. Constitutively activated Notch signaling is involved in survival and apoptosis resistance of B-CLL cells. Blood (2009) 113:856-65. doi: 10.1182/blood-2008-02-139725

54. Fabbri G, Holmes AB, Viganotti M, Scuoppo C, Belver L, Herranz $\mathrm{D}$, et al. Common nonmutational NOTCH1 activation in chronic lymphocytic leukemia. Proc Natl Acad Sci USA. (2017) 114:E2911-9. doi: 10.1073/pnas.1702564114

55. Onaindia A, Gomez S, Piris-Villaespesa M, Martinez-Laperche C, Cereceda L, Montes-Moreno S, et al. Chronic lymphocytic leukemia cells in lymph nodes show frequent NOTCH1 activation. Haematologica (2015) 100:e2003. doi: 10.3324/haematol.2014.117705

56. Nwabo Kamdje AH, Bassi G, Pacelli L, Malpeli G, Amati E, Nichele I, et al. Role of stromal cell-mediated Notch signaling in CLL resistance to chemotherapy. Blood Cancer J. (2012) 2:e73. doi: 10.1038/bcj.2012.17

57. Arruga F, Gizdic B, Serra S, Vaisitti T, Ciardullo C, Coscia M, et al. Functional impact of NOTCH1 mutations in chronic lymphocytic leukemia. Leukemia (2014) 28:1060-70. doi: 10.1038/leu.2013.319

58. Benedetti D, Tissino E, Pozzo F, Bittolo T, Caldana C, Perini C, et al. NOTCH1 mutations are associated with high CD49d expression in chronic lymphocytic leukemia: link between the NOTCH1 and the NF-kappaB pathways. Leukemia (2018) 32:654-62. doi: 10.1038/leu.2017.296

59. Pozzo F, Bittolo T, Vendramini E, Bomben R, Bulian P, Rossi FM, et al. NOTCH1-mutated chronic lymphocytic leukemia cells are characterized by a MYC-related overexpression of nucleophosmin 1 and ribosome-associated components. Leukemia (2017) 31:2407-15. doi: 10.1038/leu.2017.90

60. Jitschin R, Braun M, Qorraj M, Saul D, Le Blanc K, Zenz T, et al. Stromal cell-mediated glycolytic switch in CLL cells involves Notch-c-Myc signaling. Blood (2015) 125:3432-6. doi: 10.1182/blood-2014-10-607036

61. Puente XS, Pinyol M, Quesada V, Conde L, Ordonez GR, Villamor N, et al. Whole-genome sequencing identifies recurrent mutations in chronic lymphocytic leukaemia. Nature (2011) 475:101-5. doi: 10.1038/nature 10113

62. Fabbri G, Rasi S, Rossi D, Trifonov V, Khiabanian H, Ma J, et al. Analysis of the chronic lymphocytic leukemia coding genome: role of NOTCH1 mutational activation. J Exp Med. (2011) 208:1389-401. doi: 10.1084/jem.20110921

63. Di Ianni M, Baldoni S, Rosati E, Ciurnelli R, Cavalli L, Martelli MF, et al. A new genetic lesion in B-CLL: a NOTCH1 PEST domain mutation. $\mathrm{Br} \mathrm{J}$ Haematol. (2009) 146:689-91. doi: 10.1111/j.1365-2141.2009.07816.x

64. Sportoletti P, Baldoni S, Del Papa B, Cantaffa R, Ciurnelli R, Aureli $\mathrm{P}$, et al. A novel NOTCH1 PEST domain mutation in a case of chronic lymphocytic leukemia. Leuk Lymphoma (2013) 54:1780-2. doi: $10.3109 / 10428194.2012 .749405$

65. Puente XS, Bea S, Valdes-Mas R, Villamor N, Gutierrez-Abril J, MartinSubero JI, et al. Non-coding recurrent mutations in chronic lymphocytic leukaemia. Nature (2015) 526:519-24. doi: 10.1038/nature14666
66. Arruga F, Gizdic B, Bologna C, Cignetto S, Buonincontri R, Serra S, et al. Mutations in NOTCH1 PEST domain orchestrate CCL19-driven homing of chronic lymphocytic leukemia cells by modulating the tumor suppressor gene DUSP22. Leukemia (2017) 31:1882-93. doi: 10.1038/leu.2016.383

67. Weng AP, Ferrando AA, Lee W, Morris JP, Silverman LB, et al. Activating mutations of NOTCH1 in human T cell acute lymphoblastic leukemia. Science (2004) 306:269-71. doi: 10.1126/science.1102160

68. Villamor N, Conde L, Martinez-Trillos A, Cazorla M, Navarro A, Bea S, et al. NOTCH1 mutations identify a genetic subgroup of chronic lymphocytic leukemia patients with high risk of transformation and poor outcome. Leukemia (2013) 27:1100-6. doi: 10.1038/leu.2012.357

69. Lopez-Guerra M, Xargay-Torrent S, Rosich L, Montraveta A, Roldan J, Matas-Cespedes A, et al. The gamma-secretase inhibitor PF-03084014 combined with fludarabine antagonizes migration, invasion and angiogenesis in NOTCH1-mutated CLL cells. Leukemia (2015) 29:96-106. doi: 10.1038/leu.2014.143

70. Stilgenbauer S, Schnaiter A, Paschka P, Zenz T, Rossi M, Dohner K, et al. Gene mutations and treatment outcome in chronic lymphocytic leukemia: results from the CLL8 trial. Blood (2014) 123:3247-54. doi: 10.1182/blood-2014-01-546150

71. Pozzo F, Bittolo T, Arruga F, Bulian P, Macor P, Tissino E, et al. NOTCH1 mutations associate with low CD20 level in chronic lymphocytic leukemia: evidence for a NOTCH1 mutation-driven epigenetic dysregulation. Leukemia (2016) 30:182-9. doi: 10.1038/leu.2015.182

72. Nadeu F, Clot G, Delgado J, Martin-Garcia D, Baumann T, Salaverria I, et al. Clinical impact of the subclonal architecture and mutational complexity in chronic lymphocytic leukemia. Leukemia (2018) 32:645-53. doi: 10.1038/leu.2017.291

73. Lionetti M, Fabris S, Cutrona G, Agnelli L, Ciardullo C, Matis S, et al. Highthroughput sequencing for the identification of NOTCH1 mutations in early stage chronic lymphocytic leukaemia: biological and clinical implications. $B r$ J Haematol. (2014) 165:629-39. doi: 10.1111/bjh.12800

74. Barrio S, Shanafelt TD, Ojha J, Chaffee KG, Secreto C, Kortum KM, et al. Genomic characterization of high-count MBL cases indicates that early detection of driver mutations and subclonal expansion are predictors of adverse clinical outcome. Leukemia (2017) 31:170-6. doi: 10.1038/leu.2016.172

75. Damm F, Mylonas E, Cosson A, Yoshida K, Della Valle V, Mouly E, et al. Acquired initiating mutations in early hematopoietic cells of CLL patients. Cancer Discov. (2014) 4:1088-101. doi: 10.1158/2159-8290.CD-1 4-0104

76. Quijada-Alamo M, Hernandez-Sanchez M, Robledo C, Hernandez-Sanchez JM, Benito R, Montano A, et al. Next-generation sequencing and FISH studies reveal the appearance of gene mutations and chromosomal abnormalities in hematopoietic progenitors in chronic lymphocytic leukemia. J Hematol Oncol. (2017) 10:83. doi: 10.1186/s13045-017-0 450-y

77. Ouillette P, Saiya-Cork K, Seymour E, Li C, Shedden K, Malek SN. Clonal evolution, genomic drivers, and effects of therapy in chronic lymphocytic leukemia. Clin Cancer Res. (2013) 19:2893-904. doi: 10.1158/1078-0432.CCR-13-0138

78. Rasi S, Khiabanian H, Ciardullo C, Terzi-di-Bergamo L, Monti S, Spina $\mathrm{V}$, et al. Clinical impact of small subclones harboring NOTCH1, SF3B1 or BIRC3 mutations in chronic lymphocytic leukemia. Haematologica (2016) 101:e135-8. doi: 10.3324/haematol.2015.136051

79. Nadeu F, Delgado J, Royo C, Baumann T, Stankovic T, Pinyol M, et al. Clinical impact of clonal and subclonal TP53, SF3B1, BIRC3, NOTCH1, and ATM mutations in chronic lymphocytic leukemia. Blood (2016) 127:2122-30. doi: 10.1182/blood-2015-07-659144

80. He F, Wang L, Hu XB, Yin DD, Zhang P, Li GH, et al. Notch and BCR signaling synergistically promote the proliferation of Raji B-lymphoma cells. Leuk Res. (2009) 33:798-802. doi: 10.1016/j.leukres.2008.09.016

81. Mirandola L, Basile A, Comi P, Chiaramonte R. Burkitt lymphoma translocation turns Notch over to the dark side. Leuk Res. (2009) 33:750-1. doi: 10.1016/j.leukres.2008.10.002

82. Tohda S, Sato T, Kogoshi H, Fu L, Sakano S, Nara N. Establishment of a novel B-cell lymphoma cell line with suppressed growth by gamma-secretase inhibitors. Leuk Res. (2006) 30:1385-90. doi: 10.1016/j.leukres.2006.05.003 
83. Lee SY, Kumano K, Nakazaki K, Sanada M, Matsumoto A, Yamamoto $\mathrm{G}$, et al. Gain-of-function mutations and copy number increases of Notch2 in diffuse large B-cell lymphoma. Cancer Sci (2009) 100:920-6. doi: 10.1111/j.1349-7006.2009.01130.x

84. Nefedova Y, Cheng P, Alsina M, Dalton WS, Gabrilovich DI. Involvement of Notch-1 signaling in bone marrow stroma-mediated de novo drug resistance of myeloma and other malignant lymphoid cell lines. Blood (2004) 103:350310. doi: 10.1182/blood-2003-07-2340

85. Nefedova Y, Sullivan DM, Bolick SC, Dalton WS, Gabrilovich DI. Inhibition of Notch signaling induces apoptosis of myeloma cells and enhances sensitivity to chemotherapy. Blood (2008) 111:2220-9. doi: 10.1182/blood-2007-07-102632

86. Goy A, Kahl B. Mantle cell lymphoma: the promise of new treatment options. Crit Rev Oncol Hematol. (2011) 80:69-86. doi: 10.1016/j.critrevonc.2010.09.003

87. Herrmann A, Hoster E, Zwingers T, Brittinger G, Engelhard M, Meusers $\mathrm{P}$, et al. Improvement of overall survival in advanced stage mantle cell lymphoma. J Clin Oncol. (2009) 27:511-8. doi: 10.1200/JCO.2008. 16.8435

88. Martin P, Chadburn A, Christos P, Weil K, Furman RR, Ruan J, et al. Outcome of deferred initial therapy in mantle-cell lymphoma. J Clin Oncol. (2009) 27:1209-13. doi: 10.1200/JCO.2008.19.6121

89. Royo C, Salaverria I, Hartmann EM, Rosenwald A, Campo E, Bea S. The complex landscape of genetic alterations in mantle cell lymphoma. Semin Cancer Biol. (2011) 21:322-34. doi: 10.1016/j.semcancer.2011.09.007

90. Jares P, Colomer D, Campo E. Molecular pathogenesis of mantle cell lymphoma. J Clin Invest. (2012) 122:3416-23. doi: 10.1172/JCI61272

91. Greiner TC, Dasgupta C, Ho VV, Weisenburger DD, Smith LM, Lynch JC, et al. Mutation and genomic deletion status of ataxia telangiectasia mutated (ATM) and p53 confer specific gene expression profiles in mantle cell lymphoma. Proc Natl Acad Sci USA. (2006) 103:2352-7. doi: 10.1073/pnas.0510441103

92. Hartmann EM, Campo E, Wright G, Lenz G, Salaverria I, Jares P, et al. Pathway discovery in mantle cell lymphoma by integrated analysis of high-resolution gene expression and copy number profiling. Blood (2010) 116:953-61. doi: 10.1182/blood-2010-01-263806

93. Kridel R, Meissner B, Rogic S, Boyle M, Telenius A, Woolcock B, et al. Whole transcriptome sequencing reveals recurrent NOTCH1 mutations in mantle cell lymphoma. Blood (2012) 119:1963-71. doi: 10.1182/blood-2011-11-391474

94. Ryan RJH, Petrovic J, Rausch DM, Zhou Y, Lareau CA, Kluk MJ, et al. A $\mathrm{B}$ cell regulome links Notch to downstream oncogenic pathways in small B cell lymphomas. Cell Rep. (2017) 21:784-97. doi: 10.1016/j.celrep.2017. 09.066

95. Bea S, Valdes-Mas R, Navarro A, Salaverria I, Martin-Garcia D, Jares $\mathrm{P}$, et al. Landscape of somatic mutations and clonal evolution in mantle cell lymphoma. Proc Natl Acad Sci USA. (2013) 110:18250-5. doi: 10.1073/pnas.1314608110

96. Victora GD, Dominguez-Sola D, Holmes AB, Deroubaix S, Dalla-Favera R, Nussenzweig MC. Identification of human germinal center light and dark zone cells and their relationship to human B-cell lymphomas. Blood (2012) 120:2240-8, doi: 10.1182/blood-2012-03-415380

97. Kridel R, Mottok A, Farinha P, Ben-Neriah S, Ennishi D, Zheng Y, et al. Cell of origin of transformed follicular lymphoma. Blood (2015) 126:2118-27. doi: 10.1182/blood-2015-06-649905

98. Bachy E, Houot R, Morschhauser F, Sonet A, Brice P, Belhadj K, et al. Longterm follow up of the FL2000 study comparing CHVP-interferon to CHVPinterferon plus rituximab in follicular lymphoma. Haematologica (2013) 98:1107-14. doi: 10.3324/haematol.2012.082412

99. Junlen HR, Peterson S, Kimby E, Lockmer S, Linden O, Nilsson-Ehle H, et al. Follicular lymphoma in Sweden: nationwide improved survival in the rituximab era, particularly in elderly women: a Swedish Lymphoma Registry study. Leukemia (2015) 29:668-76. doi: 10.1038/leu.2014.251

100. Link BK, Maurer MJ, Nowakowski GS, Ansell SM, Macon WR, Syrbu SI, et al. Rates and outcomes of follicular lymphoma transformation in the immunochemotherapy era: a report from the University of Iowa/MayoClinic Specialized Program of Research Excellence Molecular Epidemiology
Resource. J Clin Oncol. (2013) 31:3272-8. doi: 10.1200/JCO.2012. 48.3990

101. Piccaluga PP, Sapienza MR, Agostinelli C, Sagramoso C, Mannu C, Sabattini E, et al. Biology and treatment of follicular lymphoma. Expert Rev Hematol. (2009) 2:533-47. doi: 10.1586/ehm.09.49

102. Kridel R, Sehn LH, Gascoyne RD. Pathogenesis of follicular lymphoma. J Clin Invest. (2012) 122:3424-31. doi: 10.1172/JCI63186

103. Green MR, Gentles AJ, Nair RV, Irish JM, Kihira S, Liu CL, et al. Hierarchy in somatic mutations arising during genomic evolution and progression of follicular lymphoma. Blood (2013) 121:1604-11. doi: 10.1182/blood-2012-09-457283

104. Okosun J, Bodor C, Wang J, Araf S, Yang CY, Pan C, et al. Integrated genomic analysis identifies recurrent mutations and evolution patterns driving the initiation and progression of follicular lymphoma. Nat Genet. (2014) 46:17681. doi: $10.1038 / \mathrm{ng} .2856$

105. Pasqualucci L, Khiabanian H, Fangazio M, Vasishtha M, Messina M, Holmes $\mathrm{AB}$, et al. Genetics of follicular lymphoma transformation. Cell Rep. (2014) 6:130-40. doi: 10.1016/j.celrep.2013.12.027

106. Green MR, Kihira S, Liu CL, Nair RV, Salari R, Gentles AJ, et al. Mutations in early follicular lymphoma progenitors are associated with suppressed antigen presentation. Proc Natl Acad Sci USA. (2015) 112:E1116-25. doi: 10.1073/pnas.1501199112

107. Okosun J, Wolfson RL, Wang J, Araf S, Wilkins L, Castellano BM, et al. Recurrent mTORC1-activating RRAGC mutations in follicular lymphoma. Nat Genet. (2016) 48:183-8. doi: 10.1038/ng.3473

108. Rosenquist R, Bea S, Du MQ, Nadel B, Pan-Hammarstrom Q. Genetic landscape and deregulated pathways in B-cell lymphoid malignancies. $J$ Intern Med. (2017) 282:371-94. doi: 10.1111/joim.12633

109. McCabe MT, Ott HM, Ganji G, Korenchuk S, Thompson C, Van Aller GS, et al. EZH2 inhibition as a therapeutic strategy for lymphoma with EZH2 activating mutations. Nature (2012) 492:108-12. doi: 10.1038/nature11606

110. Zhang J, Dominguez-Sola D, Hussein S, Lee JE, Holmes AB, Bansal $\mathrm{M}$, et al. Disruption of KMT2D perturbs germinal center B cell development and promotes lymphomagenesis. Nat Med. (2015) 21:1190-8. doi: $10.1038 / \mathrm{nm} .3940$

111. Cardenas MG, Yu W, Beguelin W, Teater MR, Geng H, Goldstein RL, et al. Rationally designed BCL6 inhibitors target activated B cell diffuse large B cell lymphoma. J Clin Invest. (2016) 126:3351-62. doi: 10.1172/JCI85795

112. Jiang Y, Ortega-Molina A, Geng H, Ying HY, Hatzi K, Parsa $\mathrm{S}$, et al. CREBBP Inactivation Promotes the Development of HDAC3-Dependent Lymphomas. Cancer Discov. (2017) 7:38-53. doi: 10.1158/2159-8290.CD-16-0975

113. Karube K, Martinez D, Royo C, Navarro A, Pinyol M, Cazorla M, et al. Recurrent mutations of NOTCH genes in follicular lymphoma identify a distinctive subset of tumours. J Pathol. (2014) 234:423-30. doi: $10.1002 /$ path.4428

114. Rossi D, Trifonov V, Fangazio M, Bruscaggin A, Rasi S, Spina V, et al. The coding genome of splenic marginal zone lymphoma: activation of NOTCH2 and other pathways regulating marginal zone development. J Exp Med. (2012) 209:1537-51. doi: 10.1084/jem.20120904

115. Krysiak K, Gomez F, White BS, Matlock M, Miller CA, Trani L, et al. Recurrent somatic mutations affecting B-cell receptor signaling pathway genes in follicular lymphoma. Blood (2017) 129:473-83. doi: 10.1182/blood-2016-07-729954

116. Hozumi K, Negishi N, Suzuki D, Abe N, Sotomaru Y, Tamaoki N, et al. Deltalike 1 is necessary for the generation of marginal zone B cells but not $\mathrm{T}$ cells in vivo. Nat Immunol (2004) 5:638-44. doi: 10.1038/ni1075

117. Maillard I, Weng AP, Carpenter AC, Rodriguez CG, Sai H, Xu L, et al. Mastermind critically regulates Notch-mediated lymphoid cell fate decisions. Blood (2004) 104:1696-702. doi: 10.1182/blood-2004-0 2-0514

118. Valls E, Lobry C, Geng H, Wang L, Cardenas M, Rivas M, et al. BCL6 Antagonizes NOTCH2 to maintain survival of human follicular lymphoma cells. Cancer Discov. (2017) 7:506-21. doi: 10.1158/2159-8290.CD-1 6-1189

119. Kochert K, Ullrich K, Kreher S, Aster JC, Kitagawa M, Johrens K, et al. Highlevel expression of Mastermind-like 2 contributes to aberrant activation of 
the NOTCH signaling pathway in human lymphomas. Oncogene (2011) 30:1831-40. doi: 10.1038/onc.2010.544

120. Stanelle J, Doring C, Hansmann ML, Kuppers R. Mechanisms of aberrant GATA3 expression in classical Hodgkin lymphoma and its consequences for the cytokine profile of Hodgkin and Reed/Sternberg cells. Blood (2010) 116:4202-11. doi: 10.1182/blood-2010-01-265827

121. Schwarzer R, Jundt F. Notch and NF- $\mathrm{KB}$ signaling pathways in the biology of classical Hodgkin lymphoma. Curr Mol Med. (2011) 11:236-45. doi: 10.2174/156652411795243423

122. Cao Z, Ding BS, Guo P, Lee SB, Butler JM, Casey SC, et al. Angiocrine factors deployed by tumor vascular niche induce B cell lymphoma invasiveness and chemoresistance. Cancer Cell (2014) 25:350-65. doi: 10.1016/j.ccr.2014.02.005

123. Swerdlow SH CE, Harris NL, Jaffe ES, Pileri SA, Stein H, Thiele J, et al. WHO Classification of Tumors of Haematopoietic and Lymphoid Tissues. 4th ed. Copenhagen (2008).

124. Roschewski M, Staudt LM, Wilson WH. Diffuse large B-cell lymphomatreatment approaches in the molecular era. Nat Rev Clin Oncol. (2014) 11:12-23. doi: 10.1038/nrclinonc.2013.197

125. Basso K, Dalla-Favera R. Germinal centres and B cell lymphomagenesis. Nat Rev Immunol. (2015) 15:172-84. doi: 10.1038/nri3814

126. Alizadeh AA, Eisen MB, Davis RE, Ma C, Lossos IS, Rosenwald A, et al. Distinct types of diffuse large B-cell lymphoma identified by gene expression profiling. Nature (2000) 403:503-11. doi: 10.1038/35000501

127. Lenz G, Wright G, Dave SS, Xiao W, Powell J, Zhao H, et al. Stromal gene signatures in large-B-cell lymphomas. N Engl J Med. (2008) 359:2313-23. doi: 10.1056/NEJMoa0802885

128. Pasqualucci L, Trifonov V, Fabbri G, Ma J, Rossi D, Chiarenza A, et al. Analysis of the coding genome of diffuse large B-cell lymphoma. Nat Genet. (2011) 43:830-7. doi: 10.1038/ng.892

129. Lohr JG, Stojanov P, Lawrence MS, Auclair D, Chapuy B, Sougnez C, et al. Discovery and prioritization of somatic mutations in diffuse large B-cell lymphoma (DLBCL) by whole-exome sequencing. Proc Natl Acad Sci USA. (2012) 109:3879-84. doi: 10.1073/pnas.1121343109

130. Morin RD, Mungall K, Pleasance E, Mungall AJ, Goya R, Huff $\mathrm{RD}$, et al. Mutational and structural analysis of diffuse large B-cell lymphoma using whole-genome sequencing. Blood (2013) 122:1256-65. doi: 10.1182/blood-2013-02-483727

131. Pasqualucci L, Dalla-Favera R. The genetic landscape of diffuse large B-cell lymphoma. Semin Hematol. (2015) 52:67-76. doi: 10.1053/j.seminhematol.2015.01.005

132. Mareschal S, Dubois S, Viailly PJ, Bertrand P, Bohers E, Maingonnat $\mathrm{C}$, et al. Whole exome sequencing of relapsed/refractory patients expands the repertoire of somatic mutations in diffuse large B-cell lymphoma. Genes Chromosomes Cancer (2016) 55:251-67. doi: 10.1002/gcc. 22328

133. Morin RD, Assouline S, Alcaide M, Mohajeri A, Johnston RL, Chong L, et al. Genetic landscapes of relapsed and refractory diffuse large B-cell lymphomas. Clin Cancer Res. (2016) 22:2290-300. doi: 10.1158/1078-0432.CCR-1 5-2123

134. Chapuy B, Stewart C, Dunford AJ, Kim J, Kamburov A, Redd RA, et al. Molecular subtypes of diffuse large B cell lymphoma are associated with distinct pathogenic mechanisms and outcomes. Nat Med. (2018) 24:679-90. doi: 10.1038/s41591-018-0016-8

135. Schmitz R, Wright GW, Huang DW, Johnson CA, Phelan JD, Wang JQ, et al. Genetics and Pathogenesis of Diffuse Large B-Cell Lymphoma. N Engl J Med. (2018) 378:1396-407. doi: 10.1056/NEJMoa1801445

136. Mo JS, Ann EJ, Yoon JH, Jung J, Choi YH, Kim HY, et al. Serum- and glucocorticoid-inducible kinase 1 (SGK1) controls Notch1 signaling by downregulation of protein stability through Fbw7 ubiquitin ligase. J Cell Sci. (2011) 124(Pt 1):100-12. doi: 10.1242/jcs.073924

137. Mo JS, Yoon JH, Hong JA, Kim MY, Ann EJ, Ahn JS, et al. Phosphorylation of nicastrin by SGK1 leads to its degradation through lysosomal and proteasomal pathways. PLoS ONE (2012) 7:e37111. doi: 10.1371/journal.pone.0037111

138. Karube K, Enjuanes A, Dlouhy I, Jares P, Martin-Garcia D, Nadeu F, et al. Integrating genomic alterations in diffuse large B-cell lymphoma identifies new relevant pathways and potential therapeutic targets. Leukemia (2018) 32:675-84. doi: 10.1038/leu.2017.251

139. Rossi D, Gaidano G. Richter syndrome: molecular insights and clinical perspectives. Hematol Oncol. (2009) 27:1-10. doi: 10.1002/hon.880

140. Rossi D, Spina V, Deambrogi C, Rasi S, Laurenti L, Stamatopoulos K, et al. The genetics of Richter syndrome reveals disease heterogeneity and predicts survival after transformation. Blood (2011) 117:3391-401. doi: 10.1182/blood-2010-09-302174

141. Tsimberidou AM, O'Brien S, Khouri I, Giles FJ, Kantarjian HM, Champlin $\mathrm{R}$, et al. Clinical outcomes and prognostic factors in patients with Richter's syndrome treated with chemotherapy or chemoimmunotherapy with or without stem-cell transplantation. J Clin Oncol. (2006) 24:2343-51. doi: 10.1200/JCO.2005.05.0187

142. Tsimberidou AM, Wierda WG, Plunkett W, Kurzrock R, O’Brien S, Wen S, et al. Phase I-II study of oxaliplatin, fludarabine, cytarabine, and rituximab combination therapy in patients with Richter's syndrome or fludarabinerefractory chronic lymphocytic leukemia. J Clin Oncol. (2008) 26:196-203. doi: 10.1200/JCO.2007.11.8513

143. Fabbri G, Khiabanian H, Holmes AB, Wang J, Messina M, Mullighan CG, et al. Genetic lesions associated with chronic lymphocytic leukemia transformation to Richter syndrome. J Exp Med. (2013) 210:2273-88. doi: 10.1084/jem.20131448

144. Parikh SA, Shanafelt TD. Risk factors for Richter syndrome in chronic lymphocytic leukemia. Curr Hematol Malig Rep. (2014) 9:294-9. doi: 10.1007/s11899-014-0223-4

145. Palomero T, Lim WK, Odom DT, Sulis ML, Real PJ, Margolin A, et al. NOTCH1 directly regulates c-MYC and activates a feed-forwardloop transcriptional network promoting leukemic cell growth. Proc Natl Acad Sci USA. (2006) 103:18261-6. doi: 10.1073/pnas.06061 08103

146. Vaisitti T, Braggio E, Allan JN, Arruga F, Serra S, Zamo A, et al. Novel richter syndrome xenograft models to study genetic architecture, biology, and therapy responses. Cancer Res. (2018) 78:3413-20. doi: 10.1158/0008-5472.CAN-17-4004

147. Rasi S, Spina V, Bruscaggin A, Vaisitti T, Tripodo C, Forconi F, et al. A variant of the LRP4 gene affects the risk of chronic lymphocytic leukaemia transformation to Richter syndrome. Br J Haematol. (2011) 152:284-94. doi: 10.1111/j.1365-2141.2010.08482.x

148. Aydin S, Rossi D, Bergui L, D’Arena G, Ferrero E, Bonello L, et al. CD38 gene polymorphism and chronic lymphocytic leukemia: a role in transformation to Richter syndrome? Blood (2008) 111:5646-53. doi: 10.1182/blood-2008-01-129726

149. Parikh SA, Kay NE, Shanafelt TD. How we treat Richter syndrome. Blood (2014) 123:1647-57. doi: 10.1182/blood-2013-11-516229

150. Cerutti A, Cols M, Puga I. Marginal zone B cells: virtues of innate-like antibody-producing lymphocytes. Nat Rev Immunol. (2013) 13:118-32. doi: $10.1038 / \mathrm{nri3383}$

151. Sriskandarajah P, Dearden CE. Epidemiology and environmental aspects of marginal zone lymphomas. Best Pract Res Clin Haematol. (2017) 30:84-91. doi: 10.1016/j.beha.2016.07.002

152. Dierlamm J, Pittaluga S, Wlodarska I, Stul M, Thomas J, Boogaerts M, et al. Marginal zone B-cell lymphomas of different sites share similar cytogenetic and morphologic features. Blood (1996) 87:299-307.

153. Rinaldi A, Mian M, Chigrinova E, Arcaini L, Bhagat G, Novak U, et al. Genome-wide DNA profiling of marginal zone lymphomas identifies subtype-specific lesions with an impact on the clinical outcome. Blood (2011) 117:1595-604. doi: 10.1182/blood-2010-01-264275

154. Johansson P, Klein-Hitpass L, Grabellus F, Arnold G, Klapper W, Pfortner $\mathrm{R}$, et al. Recurrent mutations in NF-kappaB pathway components, KMT2D, and NOTCH1/2 in ocular adnexal MALT-type marginal zone lymphomas. Oncotarget (2016) 7:62627-39. doi: 10.18632/oncotarget. 11548

155. Jung H, Yoo HY, Lee SH, Shin S, Kim SC, Lee S, et al. The mutational landscape of ocular marginal zone lymphoma identifies frequent alterations in TNFAIP3 followed by mutations in TBL1XR1 and CREBBP. Oncotarget (2017) 8:17038-49. doi: 10.18632/oncotarget. 14928 
156. Moody S, Escudero-Ibarz L, Wang M, Clipson A, Ochoa Ruiz E, DunnWalters D, et al. Significant association between TNFAIP3 inactivation and biased immunoglobulin heavy chain variable region 4-34 usage in mucosa-associated lymphoid tissue lymphoma. J Pathol. (2017) 243:3-8. doi: $10.1002 /$ path.4933

157. Troen G, Wlodarska I, Warsame A, Hernandez Llodra S, De Wolf-Peeters C, Delabie J. NOTCH2 mutations in marginal zone lymphoma. Haematologica (2008) 93:1107-9. doi: 10.3324/haematol. 11635

158. Honma K, Tsuzuki S, Nakagawa M, Tagawa H, Nakamura S, Morishima $\mathrm{Y}$, et al. TNFAIP3/A20 functions as a novel tumor suppressor gene in several subtypes of non-Hodgkin lymphomas. Blood (2009) 114:2467-75. doi: 10.1182/blood-2008-12-194852

159. Novak U, Rinaldi A, Kwee I, Nandula SV, Rancoita PM, Compagno $\mathrm{M}$, et al. The NF-\{kappa\}B negative regulator TNFAIP3 (A20) is inactivated by somatic mutations and genomic deletions in marginal zone lymphomas. Blood (2009) 113:4918-21. doi: 10.1182/blood-2008-08-1 74110

160. Rossi D, Deaglio S, Dominguez-Sola D, Rasi S, Vaisitti T, Agostinelli $\mathrm{C}$, et al. Alteration of BIRC3 and multiple other NF-кB pathway genes in splenic marginal zone lymphoma. Blood (2011) 118:4930-4. doi: 10.1182/blood-2011-06-359166

161. Olszewski AJ, Castillo JJ. Survival of patients with marginal zone lymphoma: analysis of the surveillance, epidemiology, and end results database. Cancer (2013) 119:629-38. doi: 10.1002/cncr.27773

162. Zucca E, Bertoni F, Vannata B, Cavalli F. Emerging role of infectious etiologies in the pathogenesis of marginal zone B-cell lymphomas. Clin Cancer Res. (2014) 20:5207-16. doi: 10.1158/1078-0432.CCR-1 4-0496

163. Zucca E, Bertoni F. The spectrum of MALT lymphoma at different sites: biological and therapeutic relevance. Blood (2016) 127:2082-92. doi: 10.1182/blood-2015-12-624304

164. Spina V, Rossi D. Molecular pathogenesis of splenic and nodal marginal zone lymphoma. Best Pract Res Clin Haematol. (2017) 30:5-12. doi: 10.1016/j.beha.2016.09.004

165. Kuroda K, Han H, Tani S, Tanigaki K, Tun T, Furukawa T, et al. Regulation of marginal zone B cell development by MINT, a suppressor of Notch/RBP-J signaling pathway. Immunity (2003) 18:301-12. doi: 10.1016/S1074-7613(03)00029-3

166. Moran ST, Cariappa A, Liu H, Muir B, Sgroi D, Boboila C, et al. Synergism between NF-kappa $\mathrm{B} 1 / \mathrm{p} 50$ and Notch2 during the development of marginal zone B lymphocytes. J Immunol. (2007) 179:195-200.doi: 10.4049/jimmunol.179.1.195

167. Pillai S, Cariappa A. The follicular versus marginal zone B lymphocyte cell fate decision. Nat Rev Immunol. (2009) 9:767-77. doi: 10.1038/nri2656

168. Hampel F, Ehrenberg S, Hojer C, Draeseke A, Marschall-Schroter G, Kuhn $\mathrm{R}$, et al. CD19-independent instruction of murine marginal zone B-cell development by constitutive Notch2 signaling. Blood (2011) 118:6321-31. doi: 10.1182/blood-2010-12-325944

169. Kiel MJ, Velusamy T, Betz BL, Zhao L, Weigelin HG, Chiang MY, et al. Whole-genome sequencing identifies recurrent somatic NOTCH2 mutations in splenic marginal zone lymphoma. J Exp Med. (2012) 209:1553-65. doi: 10.1084/jem.20120910

170. Arcaini L, Rossi D, Paulli M. Splenic marginal zone lymphoma: from genetics to management. Blood (2016) 127:2072-81. doi: 10.1182/blood-2015-11-624312

171. Wang L, Lawrence MS, Wan Y, Stojanov P, Sougnez C, Stevenson $\mathrm{K}$, et al. SF3B1 and other novel cancer genes in chronic lymphocytic leukemia. N Engl J Med. (2011) 365:2497-506. doi: 10.1056/NEJMoal 109016

172. Parry M, Rose-Zerilli MJ, Gibson J, Ennis S, Walewska R, Forster J, et al. Whole exome sequencing identifies novel recurrently mutated genes in patients with splenic marginal zone lymphoma. PLoS ONE (2013) 8:e83244. doi: 10.1371/journal.pone.0083244

173. Martinez N, Almaraz C, Vaque JP, Varela I, Derdak S, Beltran S, et al. Wholeexome sequencing in splenic marginal zone lymphoma reveals mutations in genes involved in marginal zone differentiation. Leukemia (2014) 28:133440. doi: 10.1038/leu.2013.365
174. Parry M, Rose-Zerilli MJ, Ljungstrom V, Gibson J, Wang J, Walewska R, et al. Genetics and prognostication in splenic marginal zone lymphoma: revelations from deep sequencing. Clin Cancer Res. (2015) 21:4174-83. doi: 10.1158/1078-0432.CCR-14-2759

175. Li J, Li J, Yang X, Qin H, Zhou P, Liang Y, et al. The C terminus of MINT forms homodimers and abrogates MINT-mediated transcriptional repression. Biochim Biophys Acta (2005) 1729:50-6. doi: 10.1016/j.bbaexp.2005. 02.001

176. VanderWielen BD, Yuan Z, Friedmann DR, Kovall RA. Transcriptional repression in the Notch pathway: thermodynamic characterization of CSLMINT (Msx2-interacting nuclear target protein) complexes. J Biol Chem. (2011) 286:14892-902. doi: 10.1074/jbc.M110.181156

177. Izon DJ, Aster JC, He Y, Weng A, Karnell FG, Patriub V, et al. Deltex1 redirects lymphoid progenitors to the B cell lineage by antagonizing Notch1. Immunity (2002) 16:231-43. doi: 10.1016/S1074-7613(02)00271-6

178. Thieblemont C, Davi F, Noguera ME, Briere J. Non-MALT marginal zone lymphoma. Curr Opin Hematol. (2011) 18:273-9. doi: 10.1097/MOH.0b013e3283477815

179. Spina V, Khiabanian H, Messina M, Monti S, Cascione L, Bruscaggin A, et al. The genetics of nodal marginal zone lymphoma. Blood (2016) 128:1362-73. doi: 10.1182/blood-2016-02-696757

180. Palumbo A, Anderson K. Multiple myeloma. N Engl J Med. (2011) 364:104660. doi: 10.1056/NEJMra1011442

181. Kyle RA, Rajkumar SV. Multiple myeloma. N Engl J Med. (2004) 351:1860 73. doi: 10.1056/NEJMra041875

182. Kuehl WM, Bergsagel PL. Molecular pathogenesis of multiple myeloma and its premalignant precursor. J Clin Invest. (2012) 122:3456-63. doi: 10.1172/JCI61188

183. Morgan GJ, Walker BA, Davies FE. The genetic architecture of multiple myeloma. Nat Rev Cancer (2012) 12:335-48. doi: 10.1038/nrc3257

184. Lohr JG, Stojanov P, Carter SL, Cruz-Gordillo P, Lawrence MS, Auclair $\mathrm{D}$, et al. Widespread genetic heterogeneity in multiple myeloma: implications for targeted therapy. Cancer Cell (2014) 25:91-101. doi: 10.1016/j.ccr.2013.12.015

185. Jundt F, Probsting KS, Anagnostopoulos I, Muehlinghaus G, Chatterjee M, Mathas S, et al. Jagged1-induced Notch signaling drives proliferation of multiple myeloma cells. Blood (2004) 103:3511-5. doi: 10.1182/blood-2003-07-2254

186. Skrtic A, Korac P, Kristo DR, Ajdukovic Stojisavljevic R, Ivankovic $\mathrm{D}$, Dominis M. Immunohistochemical analysis of NOTCH1 and JAGGED1 expression in multiple myeloma and monoclonal gammopathy of undetermined significance. Hum Pathol. (2010) 41:1702-10. doi: 10.1016/j.humpath.2010.05.002

187. Colombo M, Mirandola L, Platonova N, Apicella L, Basile A, Figueroa AJ, et al. Notch-directed microenvironment reprogramming in myeloma: a single path to multiple outcomes. Leukemia (2013) 27:1009-18. doi: 10.1038/leu.2013.6

188. Colombo M, Galletti S, Bulfamante G, Falleni M, Tosi D, Todoerti K, et al. Multiple myeloma-derived Jagged ligands increases autocrine and paracrine interleukin-6 expression in bone marrow niche. Oncotarget (2016) 7:5601329. doi: 10.18632/oncotarget.10820

189. Leong KG, Karsan A. Recent insights into the role of Notch signaling in tumorigenesis. Blood (2006) 107:2223-33. doi: 10.1182/blood-2005-0 8-3329

190. Mirandola L, Apicella L, Colombo M, Yu Y, Berta DG, Platonova N, et al. Anti-Notch treatment prevents multiple myeloma cells localization to the bone marrow via the chemokine system CXCR4/SDF-1. Leukemia (2013) 27:1558-66. doi: 10.1038/leu.2013.27

191. Takeuchi T, Adachi Y, Ohtsuki Y. Skeletrophin, a novel ubiquitin ligase to the intracellular region of Jagged-2, is aberrantly expressed in multiple myeloma. Am J Pathol. (2005) 166:1817-26. doi: 10.1016/S0002-9440(10)62491-1

192. Ghoshal P, Nganga AJ, Moran-Giuati J, Szafranek A, Johnson TR, Bigelow AJ, et al. Loss of the SMRT/NCoR2 corepressor correlates with JAG2 overexpression in multiple myeloma. Cancer Res. (2009) 69:4380-7. doi: 10.1158/0008-5472.CAN-08-3467

193. van Stralen E, van de Wetering M, Agnelli L, Neri A, Clevers HC, Bast BJ. Identification of primary MAFB target genes in multiple myeloma. Exp Hematol. (2009) 37:78-86. doi: 10.1016/j.exphem.2008.08.006 
194. Groth C, Fortini ME. Therapeutic approaches to modulating Notch signaling: current challenges and future prospects. Semin Cell Dev Biol. (2012) 23:465-72. doi: 10.1016/j.semcdb.2012.01.016

195. Wu Y, Cain-Hom C, Choy L, Hagenbeek TJ, de Leon GP, Chen Y, et al. Therapeutic antibody targeting of individual Notch receptors. Nature (2010) 464:1052-7. doi: 10.1038/nature08878

196. Li K, Li Y, Wu W, Gordon WR, Chang DW, Lu M, et al. Modulation of Notch signaling by antibodies specific for the extracellular negative regulatory region of NOTCH3. J Biol Chem. (2008) 283:8046-54. doi: 10.1074/jbc.M800170200

197. Hoey T, Yen WC, Axelrod F, Basi J, Donigian L, Dylla S, et al. DLL4 blockade inhibits tumor growth and reduces tumor-initiating cell frequency. Cell Stem Cell (2009) 5:168-77. doi: 10.1016/j.stem.2009.05.019

198. Moellering RE, Cornejo M, Davis TN, Del Bianco C, Aster JC, Blacklow SC, et al. Direct inhibition of the NOTCH transcription factor complex. Nature (2009) 462:182-8. doi: 10.1038/nature08543
199. Secchiero P, Voltan R, Rimondi E, Melloni E, Athanasakis E, Tisato $\mathrm{V}$, et al. The gamma-secretase inhibitors enhance the anti-leukemic activity of ibrutinib in B-CLL cells. Oncotarget (2017) 8:59235-45. doi: 10.18632/oncotarget.19494

Conflict of Interest Statement: The authors declare that the research was conducted in the absence of any commercial or financial relationships that could be construed as a potential conflict of interest.

Copyright (c) 2018 Arruga, Vaisitti and Deaglio. This is an open-access article distributed under the terms of the Creative Commons Attribution License (CC BY). The use, distribution or reproduction in other forums is permitted, provided the original author(s) and the copyright owner(s) are credited and that the original publication in this journal is cited, in accordance with accepted academic practice. No use, distribution or reproduction is permitted which does not comply with these terms. 